\title{
A FUZZY GOAL PROGRAMMING APPROACH FOR SOLVING MULTI- OBJECTIVE SUPPLY CHAIN NETWORK PROBLEMS WITH PARETO- DISTRIBUTED RANDOM VARIABLES
}

\author{
VINCENT CHARLES* \\ Professor of Management Science \\ Director of Research \\ Buckingham Business School \\ The University of Buckingham \\ Buckingham MK18 1EG \\ United Kingdom \\ v.charles@buckingham.ac.uk \\ Phone: +4407491226227 \\ *Corresponding author \\ SRIKANT GUPTA \\ Research Scholar \\ Department of Statistics \& Operations Research \\ Aligarh Muslim University, Aligarh \\ AMU Campus, Aligarh \\ Uttar Pradesh 202001 \\ India

\section{IRFAN ALI} \\ Assistant Professor \\ Department of Statistics \& Operations Research \\ Aligarh Muslim University, Aligarh \\ AMU Campus, Aligarh \\ Uttar Pradesh 202001 \\ India
}




\begin{abstract}
Uncertainty is unavoidable and addressing the same is inevitable. That everything is available at our doorstep is due to a well-managed modern global supply chain, which takes place despite its efficiency and effectiveness being threatened by various sources of uncertainty originating from the demand side, supply side, manufacturing process, and planning and control systems. This paper addresses the demand- and supply-rooted uncertainty. In order to cope with uncertainty within the constrained multi-objective supply chain network, this paper develops a fuzzy goal programming methodology, with solution procedures. The probabilistic fuzzy goal multi-objective supply chain network (PFG-MOSCN) problem is thus formulated and then solved by three different approaches, namely, simple additive goal programming approach, weighted goal programming approach, and pre-emptive goal programming approach, to obtain the optimal solution. The proposed work links fuzziness in transportation cost and delivery time with randomness in demand and supply parameters. The results may prove to be important for operational managers in manufacturing units, interested in optimizing transportation costs and delivery time, and implicitly, in optimizing profits. A numerical example is provided to illustrate the proposed model.
\end{abstract}

Keywords: Multi-Objective Optimization; Supply Chain Network; Fuzzy Set Theory; ChanceConstrained Programming; Fuzzy Goal Programming.

\title{
1. Introduction
}

The supply chain management (SCM) is nowadays considered to be a major driving factor in gaining a competitive advantage in turbulent markets. Nevertheless, its efficiency and effectiveness are being threatened by various sources of uncertainty, which may originate from the demand side, supply side, manufacturing process, and planning and control systems. Without a doubt, supply-chain uncertainty is a matter with which every manager has to cope. ${ }^{1}$ In the context in which these sources of uncertainty represent a major problem, understanding them would be of help to tackle the same systematically and proactively. This paper addresses the demand- and supplyrooted uncertainty.

In order to research supply-chain uncertainty, we must first define the related key concepts. The supply chain includes "all of those activities associated with moving goods from the raw-materials stage through to the end user". ${ }^{2}$ The organization always looks for the selection of the right supplier/vendor to bring ease in the supply chain network, but should also bring revenue to the firm with minimum transportation cost, inventory cost, rejected items, and late-delivered items. ${ }^{3}$ 


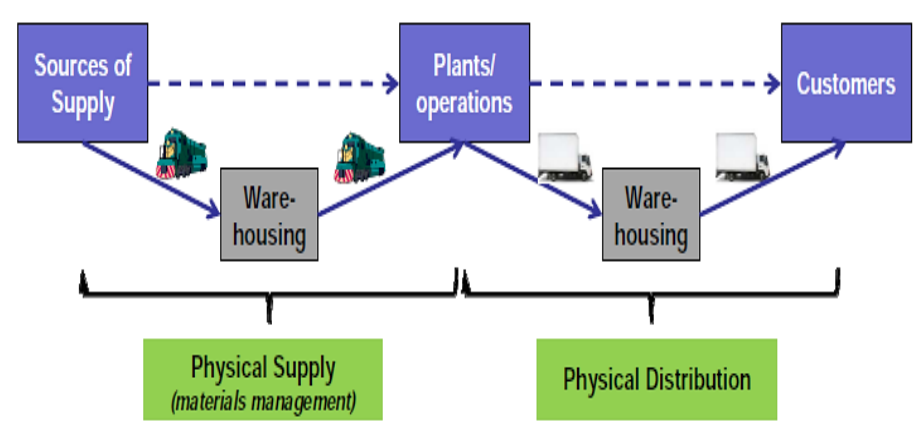

Fig. 1. Supply Chain Network.

The term supply chain network (SCN) (Fig. 1) consists of a distribution network of the product supply from source to destination, i.e., the move of the raw material from suppliers to manufacturers, from manufacturers to distributors, then from distributors to retailers, and finally, from retailers to customers. The manufacturer receives the raw material from the suppliers and after processing it into finished goods, he supplies the latter to different warehouses and retailers to make them easily available for the customers. Throughout the $20^{\text {th }}$ century, the SCN problem has been gaining importance due to the market globalization, which has increased the competition among the companies. Companies are obliged to maintain high customer services levels, while at the same time they are trying to reduce transportation costs and maintain their profit margins. Traditionally, the planning, purchasing, manufacturing, marketing, and distribution organisations along the supply chain operate independently. These organisations have their objectives, and these are often conflicting, but there is a need for a mechanism through which these different functions can be integrated together. Supply chain management is a strategy through which such integration can be achieved. ${ }^{4}$

During the formulation process of multi-criteria decision-making problems, the coefficients of the objectives and the constraints are usually specified by decision-makers (DMs). In most real-world problems, the potential values of these coefficients are vague or ambiguously known to the DMs. Accordingly, it would be more convenient for these coefficients to be represented as fuzzy numerical data. ${ }^{5-8}$ The subsequent mathematical programming problem which includes fuzzy coefficients would be seen as more factual than the traditional one. From this perspective, the coefficients exist in the objective functions, and the constraints of the problem are thought to be described by fuzzy numbers. Stochastic Programming (SP) consists of modelling uncertain optimization problems in which probability distributions governing the data are known or can be estimated using unknown parameters. This technique is a suitable mathematical tool for dealing with several real-world transportation problems (TPs). Biswas and Modak ${ }^{9}$, Roy et al. ${ }^{10}$, Mahapatra et al. ${ }^{11}$, Biswal and Samal ${ }^{12}$, and Barik $^{13}$ considered a stochastic environment, wherein the random variable follows exponential distribution, Weibull distribution, extreme value distribution, standard normal distribution, Cauchy distribution, logistic distribution, and Pareto distribution,respectively, in their formulated chance-constrained programming problem.More recently, Gupta et al ${ }^{14}$ formulated a special case of SCM by considering a capacitated transportation problem under certain and uncertain environments. They used fuzzy set theory, multi-choices technique, and probabilistic technique for the presentation of uncertainty in their formulated capacitated transportation problem and efficiently used a fuzzy goal programming approach for obtaining the optimal allocation. 
The work done here has been organized in various sections, as follows: a brief literature review on the MOSCN is given in Section 2. In Section 3, the formulation of MOSCN with fuzzy coefficient has been provided. Section 4 presents the fuzzy goal programming and probabilistic fuzzy goal programming formulation of the MOSCN with Pareto distribution. Solution approaches to the PFGP-MOSCN problem with Pareto distribution are then given in Section 5. A hypothetical numerical example is provided in Section 6 to show the efficiency of the developed methods along with the sensitivity analysis of the decision variable. Finally, in Section 7 , managerial insights and contribution, limitations, and future scope are discussed and in Section 8, conclusions are drawn based on the solutions obtained from the numerical example. After discussing the relevant introductory, we now proceed to the literature review related to supply chain network.

\section{Literature Review}

Beamon ${ }^{15}$ presented a detailed overview of the literature on multi-stage supply chain modelling which mainly focuses on deterministic, stochastic, simulation-based supply chain models in the literature. Beamon ${ }^{15}$ had distinguished between various supply chain performance measures qualitatively and quantitatively. Shen ${ }^{16}$ conducted a detailed survey and provided future research directions on integrated supply chain design models. Shen ${ }^{16}$ formulated supply chain models on profit maximization with demand flexibility, multiple commodities, unreliable supply, parameter uncertainty scenario, models on inventory cost, routing cost, capacitated distribution centres, a model with service consideration, among others. Mula et al. ${ }^{17}$ presented a review of different mathematical programming technique for SCM models and classified the different modelling approaches based on linear programming, non-linear programming, multi-objective programming, fuzzy programming, stochastic programming, and Heuristics algorithms and metaheuristics.

Many academics and practitioners have been continuously focussing on solving uncertain supply chain problems. There have been various articles published in academic journals focussing on the use of the fuzzy set theory to handle the imprecision or vagueness in multi-criteria supply chain problems. These include the work of Sabri and Beamon ${ }^{18}$, who developed an integrated model for solving multi-objective supply chain problem that integrates simultaneous strategic and operational planning together, i.e., production cost, delivery time with uncertain demand, also tries to reduce complexity by giving some reasonable simplifications. On the other hand, Bredstrom and Ronnqvist ${ }^{19}$ considered two independent mixed integer linear programming models, one for production planning, which considers transport costs, and the other one for distribution planning in a multi-period and multi-product environment. Ryu et al. ${ }^{20}$ suggested a bi-level modelling approach comprising two linear programming models with uncertain demand, one for production planning and one for distribution planning.

Park $^{21}$ further suggested an integrated transport and production planning model that uses mixed integer linear programming in a multi-site, multi-retailer, multi-product and multi-period environment with an overall objective of maximizing overall profits. Oh and Karimi ${ }^{22}$ put forward a linear programming model that integrates production and distribution planning for a multinational firm in the chemical sector in a multi-plant, multi-period, and multi-product environment. Aliev et al. ${ }^{23}$ integrated fuzzy mathematical programming with multi-period, multi-product fuzzy production, and distribution aggregate planning model in the supply chain by providing a sound trade-off between the filtrate of the fuzzy market demand and the profit. The optimization problem is solved by a genetic algorithm that provides a general near-optimal plan with more realistic results. Roghanian ${ }^{24}$ formulated a probabilistic bi-level linear supply chain planning model where market demand, production capacity, 
and resources available to all plants for each product were considered as random variables and followed a uniform distribution. Xu et al. ${ }^{25}$ proposed a spanning tree approach for random fuzzy multi-objective SC design problems with the aim of minimizing the total cost comprised of fixed costs of plants and DCs, and maximizing the customer services that can be rendered to customers in termsof acceptable delivery time. Selim and Ozkarahan ${ }^{26}$ developed a multi-objective SC distribution network design model to obtain the optimum numbers, locations, and capacity levels of plants and warehouses to deliver the products to the retailers at the least cost while satisfying the desired service level. Pishvaee and Torabi ${ }^{27}$ formulated a multi-objective possibilistic mixed integer programming model for SCN under a possibilistic environment.

Yeh and Chuang ${ }^{28}$ proposed multi-objective supply chain models for partner selection in green supply chain problems. They considered four conflicting objectives, such as minimization of total cost and minimization of total time comprised of product time and transportation time, and maximization of product quality and maximization of the green appraisal score, and solved them using two different multi-objective genetic algorithms. Liang $^{29}$ developed a fuzzy multi-objective linear programming model with fuzzy imprecise aspiration levels, which attempts to simultaneously minimize total cost and total delivery time by using a fuzzy goal programming method. Sarkar ${ }^{30}$ represented three different probabilistic production-inventory models and used an algebraic procedure to obtain the minimum cost and optimum lotsize of the entire SCM. Nasiri, et al. ${ }^{31}$ developed threeechelon supply chain models for multiple distribution centres, production sites, and suppliers with uncertain stochastic demand. Jindal ${ }^{32}$ proposed a fuzzy mixed-integer linear programming model for an optimization of a multi-product, multi-time, multi-echelon capacitated closed-loop supply chain in an uncertain environment. The uncertainty related to ill-known parameters, such as product demand, return volume, fraction of parts recovered for different product recovery processes, purchasing cost, transportation cost, inventory cost, processing, and setup cost at facility centresis handled with fuzzy numbers.

Kim and Sarkar $^{33}$ developed an SCM model with stochastic lead time demand, trade-credit policy, quality improvement of products, setup cost reduction of the supplier, and variable backorder rate. This paper aimed to minimize the total cost of the system related to overall supply chain. Sarkar et al. ${ }^{34}$ considered an assembly line manufacturing system with the primary aim to minimize the total cost of the entire SCM by simultaneously optimizing setup cost, process quality, number of deliveries, and lot size with constant demand rate. Latpate and Kurade $^{35}$ proposed a fuzzy linear programming model for supply chain network by integrating procurement, production, and distribution planning activities into a multi-echelon supply chain network. Gupta et al. ${ }^{36}$ gave an efficient fuzzy goal programming approach for solving the SCM problem. Their proposed model combined three well-known approaches, i.e., fuzzy programming, goal programming, and interactive programming, to simultaneously minimize total transportation costs and total delivery time concerning inventory levels, available initial stock at each source, as well as market demand and available warehouse space at each destination, and the constraint on the total budget under an uncertain environment.The SCM models focusing on the optimization of the inventory cost, transportation cost, and delivery time were discussed in the past by Sarkar et al. ${ }^{37}, \operatorname{Sarkar}^{38}$, Sarkar and Mahapatra ${ }^{39}$, Sarkar et al. ${ }^{40}$, and Soni et al. ${ }^{41}$.

Table 1 provides a comparison of the above-mentioned studies considering the nature of the parameters used and positions the present paper as unique in the literature. 
Table 1. Shared Process Information of the Reviewed Works.

\begin{tabular}{|c|c|c|c|}
\hline \multirow{2}{*}{ Authors and Publication Year } & \multicolumn{3}{|c|}{ Nature of Parameters } \\
\hline & Certain & Fuzzy & Probabilistic \\
\hline Sabri and Beamon ${ }^{18}$ & $\times$ & & \\
\hline Bredstrom and Ronnqvist ${ }^{19}$ & $\times$ & & \\
\hline Ryu et al. ${ }^{20}$ & $x$ & & \\
\hline Park $^{21}$ & $x$ & & \\
\hline Oh and Karimi ${ }^{22}$ & $\times$ & & \\
\hline Aliev et al. ${ }^{23}$ & $\times$ & & \\
\hline Roghanian et al. ${ }^{24}$ & $\times$ & & $x$ \\
\hline $\mathrm{Xu}$ et al. ${ }^{25}$ & $x$ & $x$ & $x$ \\
\hline Selim and Ozkarahan ${ }^{26}$ & $\times$ & $x$ & \\
\hline Pishvaee and Torabi ${ }^{27}$ & $x$ & & $x$ \\
\hline Yeh and Chuang ${ }^{28}$ & $x$ & & \\
\hline Liang $^{29}$ & $x$ & $x$ & \\
\hline Sarkar ${ }^{30}$ & $x$ & & $x$ \\
\hline Nasiri et al. ${ }^{31}$ & $x$ & & $x$ \\
\hline Jindal et al. ${ }^{32}$ & $x$ & $x$ & \\
\hline Kim and Sarkar ${ }^{33}$ & $x$ & & $x$ \\
\hline Sarkar et al. ${ }^{34}$ & $x$ & & \\
\hline Latpate and Kurade ${ }^{35}$ & $x$ & & \\
\hline Gupta et al. ${ }^{36}$ & $x$ & $x$ & \\
\hline Sarkar et al. ${ }^{37}$ & $x$ & & \\
\hline Sarkar ${ }^{38}$ & $\times$ & & \\
\hline Sarkar and Mahapatra ${ }^{39}$ & $x$ & $x$ & $x$ \\
\hline Sarkar et al. ${ }^{40}$ & $x$ & & \\
\hline Soni et al. ${ }^{41}$ & $x$ & $x$ & \\
\hline This paper & $x$ & $x$ & $x$ \\
\hline
\end{tabular}

Note: $x$ indicates the nature of parameter used in the respective paper.

In this paper, motivated by such studies in the field of SCN, a probabilistic fuzzy goal programming (PFGP) technique has been developed to solve SCN problems. Because in real-world problems, the possible values of the coefficient of transportation cost and of the delivery time are often imprecisely known to the DM, it would be indeed more appropriate to interpret the coefficient as fuzzy. Here, the parameters are represented by fuzzy 
numbers and are transformed into their deterministic form through a ranking function approach. Also, in formulating real-world problems, there may be situations when we do not precisely know the right-hand side of the constraints; to overcome this situation, we have considered that these parameters are random variables which follow a Pareto distribution with known mean and variance. Different types of goal programming models have been used to solve the formulated PFG-MOSCN problem for obtaining the optimal solution. After discussing the relevant literature related to supply chain network, we now proceed to the model formulation of the problem.

\section{The mathematical model of the multi-objective supply chain network}

Latpate and Kurade ${ }^{35}$ formulated the MOSCN model with imprecise data, wherein they considered a hypothetical system for the network. With some modification in their model formulation, we have considered the following notations which are listed below:

\section{Notations and Terminology}

The notations and terminology used are as follows:

\section{Indices}

$i$-index of retailers, $\{i=1,2, \ldots \ldots ., I\}$;

$j$-index of warehouses, $\{j=1,2, \ldots, J\}$;

$k$-index of plants, $\{k=1,2, \ldots, K\}$;

$l$-index of suppliers, $\{l=1,2, \ldots, L\}$.

\section{Parameters}

$D_{i}$ - annual demand from the $i^{\text {th }}$ retailers,

$A_{k}$ - potential capacity of the $k^{\text {th }}$ plants,

$B_{l}$ - supply capacity of the $l^{\text {th }}$ suppliers,

$E_{j}$ - potential capacity of the $j^{\text {th }}$ warehouses,

$C_{l k}-$ cost of shipping one unit from the supply source $l$ to the plant $k$,

$C_{k j}-$ cost of producing and shipping one unit from the plant $k$ to the warehouse $j$,

$C_{k i}-$ cost of producing and shipping one unit from the plant $k$ to the retailer $i$,

$C_{j i}-$ cost of shipping one unit from the warehouse $j$ to the retailer $i$,

$D_{k j}-$ delivery time of shipping one unit from the plant $k$ to the warehouse $j$,

$D_{k i}$ - delivery time of shipping one unit from the plant $k$ to the retailer $i$,

$D_{j i}$-delivery time of shipping one unit from the warehouse $j$ to the retailer $i$.

\section{Decision variables}

$W_{l k}$ - quantity shipped from the supply source $l$ to the plant $k$,

$X_{k j}$-quantity shipped from the plant $k$ to the warehouse $j$, 
$Y_{k i}$ - quantity shipped from the plant $k$ to the retailer $i$,

$Z_{j i}$-quantity shipped from the warehouse $j$ to the retailer $i$.

Using the above-defined notations, the mathematical model of MOSCN in case of a deterministic parameter is given as:

The first objective function that minimizes the transportation cost of the $\mathrm{SCN}$ is given by:

$\operatorname{Min} Z_{1}=\sum_{l=1}^{L} \sum_{k=1}^{K} C_{l k} W_{l k}+\sum_{k=1}^{K} \sum_{j=1}^{J} C_{k j} X_{k j}+\sum_{k=1}^{K} \sum_{i=1}^{I} C_{k i} Y_{k i}+\sum_{j=1}^{J} \sum_{i=1}^{I} C_{j i} Z_{j i}$,

The second objective function that minimizes the delivery time of the SCN is given by:

$\operatorname{Min} Z_{2}=\sum_{k=1}^{K} \sum_{j=1}^{J} D_{k j} X_{k j}+\sum_{k=1}^{K} \sum_{i=1}^{I} D_{k i} Y_{k i}+\sum_{j=1}^{J} \sum_{i=1}^{I} D_{j i} Z_{j i}$

subject to the following constraints:

Constraint I is the total quantity shipped from the supplier to the plant.

$\sum_{k=1}^{K} W_{l k} \leq B_{l}$,

Constraint II is the quantity produced in the factory, which cannot exceed its capacity.

$\sum_{i=1}^{I} Y_{k i}+\sum_{j=1}^{J} X_{k j} \leq A_{k}$

Constraint III isthe quantity shipped through the warehouse, which cannot exceed its capacity.

$\sum_{i=1}^{I} Z_{j i} \leq E_{j}$

Constraint IV is the quantity shipped to the retailers, which must cover the customer demand.

$\sum_{j=1}^{J} Z_{j i}+\sum_{k=1}^{K} Y_{k i} \geq D_{i}$

Constraint $\mathrm{V}$ is the total quantity shipped from the plant to the warehouse and retailers, which cannot exceed the quantity of the raw material received.

$\sum_{l=1}^{L} W_{l k} \geq \sum_{j=1}^{J} X_{k j}+\sum_{i=1}^{I} Y_{k i}$

Constraint VI isthe quantity shipped out of the warehouse to the retailers, which cannot exceed its capacity.

$\sum_{k=1}^{K} X_{k j} \geq \sum_{i=1}^{I} Z_{j i}$,

with non-negative constraints: 
$W_{l k} \geq 0, \forall l, k$,

$X_{k j} \geq 0, \forall k, j$,

$Y_{k i} \geq 0, \quad \forall k, i$

$Z_{j i} \geq 0, \forall j, i$.

In the above discussed MOSCN model, the parameters are assumed to take deterministic values, but in most of the practical situations, these may take imprecise values due to some possible reasons, as listed below:

- Price of the item might depend upon the interest of the DM. Sometimes, he might decide to spend more or less for the quantity ordered.

- Cost of shipping one unit from the source to the plant, from the plant to the retailer, from the plant to the warehouse, and from the warehouse to the retailer is not known precisely to the DM.

- Similarly, the delivery time of shipping one unit from the plant to the retailer, from the plant to the warehouse and, from the warehouse to the retailer may vary during the transportation period.

Such vagueness in the critical information cannot be captured in a deterministic problem. Thus,the optimal results obtained from these deterministic formulations may not serve the real purpose of modelling the problem. Due to this, we have considered the model with imprecise information. In light of the above discussed possible situations in the MOSCN model, the fuzzy formulation of the problem by replacing all of the deterministic parameters of $\operatorname{cost} C_{l k}, C_{k j}, C_{k i} \& C_{j i}$ and delivery time $D_{k j}, D_{k i} \& D_{j i}$ with fuzzy numbers is conventionally expressed as: 


\section{Problem (1)}

$\operatorname{Min} Z_{1}=\sum_{l=1}^{L} \sum_{k=1}^{K} \tilde{C}_{l k} W_{l k}+\sum_{k=1}^{K} \sum_{j=1}^{J} \tilde{C}_{k j} X_{k j}+\sum_{k=1}^{K} \sum_{i=1}^{I} \tilde{C}_{k i} Y_{k i}+\sum_{j=1}^{J} \sum_{i=1}^{I} \tilde{C}_{j i} Z_{j i}$

$\operatorname{Min} Z_{2}=\sum_{k=1}^{K} \sum_{j=1}^{J} \tilde{D}_{k j} X_{k j}+\sum_{k=1}^{K} \sum_{i=1}^{I} \tilde{D}_{k i} Y_{k i}+\sum_{j=1}^{J} \sum_{i=1}^{I} \tilde{D}_{j i} Z_{j i}$

s.t.

$$
\begin{array}{ll}
\sum_{k=1}^{K} W_{l k} \leq B_{l}, & \forall l, \\
\sum_{i=1}^{I} Y_{k i}+\sum_{j=1}^{J} X_{k j} \leq A_{k}, & \forall k, \\
\sum_{i=1}^{I} Z_{j i} \leq E_{j}, & \forall j, \\
\sum_{j=1}^{J} Z_{j i}+\sum_{k=1}^{K} Y_{k i} \geq D_{i}, & \forall i, \\
\sum_{l=1}^{L} W_{l k} \geq \sum_{j=1}^{J} X_{k j}+\sum_{i=1}^{I} Y_{k i}, & \forall k, \\
\sum_{k=1}^{K} X_{k j} \geq \sum_{i=1}^{I} Z_{j i}, & \\
W_{l k} \geq 0, \forall l, k, & \\
X_{k j} \geq 0, \forall k, j, & \\
Y_{k i} \geq 0, \forall k, i, & \\
Z_{j i} \geq 0, \forall j, i, &
\end{array}
$$

where all of the fuzzy parameters in Problem (1) are considered to be trapezoidal fuzzy numbers, i.e., $(m, n, \alpha, \beta)$ are trapezoidal fuzzy numbers with two defuzzifiers $m, n$, left fuzziness $\alpha>0$, and right fuzziness $\beta>0$, and they can be converted into their crisp form by using the ranking function defined in section (2.3). After discussing the model formulation of the MOSCN, we now proceed to the fuzzy goal programming and probabilistic fuzzy goal programming formulation of the MOSCN with Pareto distribution.

\section{A fuzzy goal programming model for multi-objective supply chain network}

Goal Programming (GP) is considered to be the most powerful and flexible technique that can be applied to a variety of decision-making problems involving multiple objectives. The GP model tries to optimize multiple goals simultaneously by minimizing the deviation from the objective function. GP requires the DMs to set an aspiration level for each goal, which can be an arduous task as several uncertainties in nature must also be considered. The GP technique, developed by Charnes and Cooper $^{42}$, emerged as the most powerful technique to solve such multicriteria decision-making problems. Ever since the development of the GP technique, it has been studied by many authors such as Lee ${ }^{43}$, Ignizio ${ }^{44}$ and many others, who are continuously working on the advancement of GP. On the other hand, Zadeh ${ }^{5}$ suggested the concept of fuzzy sets theory for solving the problem consisting of vague parameters. Zimmermann ${ }^{45}$ developed a fuzzy programming approach for solving ill-conditioned multi-criteria 
optimization problems. The problems consisting of imprecise and vague parameters are considered to be typical mathematical problems - in such cases, the ranking function is used to get the crisp form of the problem. Thus, the classical methods of mathematical programming fail to optimize such problems. Zadeh and Bellman ${ }^{6}$ introduced a concept according to which the constraints and goals in such situations may be viewed as fuzzy. Using Zimmermann's approach ${ }^{45}$, a typical fuzzy goal MOSCN model is expressed as follows:

\section{Problem (2)}

Find $X$ to optimize the following fuzzy goals:

$$
\begin{aligned}
& \sum_{l=1}^{L} \sum_{k=1}^{K} \tilde{C}_{l k} W_{l k}+\sum_{k=1}^{K} \sum_{j=1}^{J} \tilde{C}_{k j} X_{k j}+\sum_{k=1}^{K} \sum_{i=1}^{I} \tilde{C}_{k i} Y_{k i}+\sum_{j=1}^{J} \sum_{i=1}^{I} \tilde{C}_{j i} Z_{j i} \preceq g_{1} \\
& \sum_{k=1}^{K} \sum_{j=1}^{J} \tilde{D}_{k j} X_{k j}+\sum_{k=1}^{K} \sum_{i=1}^{I} \tilde{D}_{k i} Y_{k i}+\sum_{j=1}^{J} \sum_{i=1}^{I} \tilde{D}_{j i} Z_{j i} \preceq g_{2}
\end{aligned}
$$

S.t.

$$
\begin{array}{ll}
\sum_{k=1}^{K} W_{l k} \leq B_{l}, & \forall l, \\
\sum_{i=1}^{I} Y_{k i}+\sum_{j=1}^{J} X_{k j} \leq A_{k}, & \forall k, \\
\sum_{i=1}^{I} Z_{j i} \leq E_{j}, & \forall j, \\
\sum_{j=1}^{J} Z_{j i}+\sum_{k=1}^{K} Y_{k i} \geq D_{i}, & \forall i, \\
\sum_{l=1}^{L} W_{l k} \geq \sum_{j=1}^{J} X_{k j}+\sum_{i=1}^{I} Y_{k i}, & \forall k, \\
\sum_{k=1}^{K} X_{k j} \geq \sum_{i=1}^{I} Z_{j i}, & \\
W_{l k} \geq 0, \forall l, k, & \\
X_{k j} \geq 0, \forall k, j, & \\
Y_{k i} \geq 0, \forall k, i, & \\
Z_{j i} \geq 0, \forall j, i . &
\end{array}
$$

The symbol ' $\preceq$ '(fuzzy-min) referring to $Z_{1}(X) \& Z_{2}(X)$ should be approximately less than or equal to the aspiration level $g_{1} \& g_{2}$ respectively, which means that the DM is satisfied even if it is greater than the aspiration level up to a certain tolerance limit. 


\subsection{A probabilistic fuzzy goal programming model for multi-objective supply chain network}

In most of the practical situations, we may face the problem of not knowing the values of some or all the parameters of the mathematical programming models; such a problem comes under stochastic programming (SP). The SP problem was first formulated by Dantizg, and Mandansky ${ }^{46}$, who suggested a two-stage programming technique to determine the solutions. Later, Charnes and Cooper ${ }^{47}$ developed the chance-constrained programming (CCP) technique in which the chance constraints were converted into equivalent deterministic non-linear constraints. $\mathrm{CCP}$ is treated as a kind of SP in which some or all of the constraints of the problem involved are random variables, which need to be satisfied with a certain probability. CCP has been applied to different real-life problems having multiple and conflicting objectives. This kind of CCP problems is termed as MOCCP problems. Contini ${ }^{48}$ was the first to introduce a GP approach for solving MOCCP, which was further studied by StancuMinasian ${ }^{49}$. A MOSCN model of the PFGP can be stated as:

\section{Problem (3)}

Find $X$ to optimize the following fuzzy goals:

$$
\begin{aligned}
& \sum_{l=1}^{L} \sum_{k=1}^{K} \tilde{C}_{l k} W_{l k}+\sum_{k=1}^{K} \sum_{j=1}^{J} \tilde{C}_{k j} X_{k j}+\sum_{k=1}^{K} \sum_{i=1}^{I} \tilde{C}_{k i} Y_{k i}+\sum_{j=1}^{J} \sum_{i=1}^{I} \tilde{C}_{j i} Z_{j i} \preceq g_{1} \\
& \sum_{k=1}^{K} \sum_{j=1}^{J} \tilde{D}_{k j} X_{k j}+\sum_{k=1}^{K} \sum_{i=1}^{I} \tilde{D}_{k i} Y_{k i}+\sum_{j=1}^{J} \sum_{i=1}^{I} \tilde{D}_{j i} Z_{j i} \preceq g_{2}
\end{aligned}
$$

s.t.

$$
\begin{array}{ll}
\operatorname{Pr}\left(\sum_{k=1}^{K} W_{l k} \leq B_{l}\right) \geq 1-\alpha_{l}, & \forall l, \\
\sum_{i=1}^{I} Y_{k i}+\sum_{j=1}^{J} X_{k j} \leq A_{k}, & \forall k, \\
\sum_{i=1}^{I} Z_{j i} \leq E_{j}, & \forall j, \\
\operatorname{Pr}\left(\sum_{j=1}^{J} Z_{j i}+\sum_{k=1}^{K} Y_{k i} \geq D_{i}\right) \geq 1-\beta_{i}, & \forall i, \\
\sum_{l=1}^{L} W_{l k} \geq \sum_{j=1}^{J} X_{k j}+\sum_{i=1}^{I} Y_{k i}, & \forall k, \\
\sum_{k=1}^{K} X_{k j} \geq \sum_{i=1}^{I} Z_{j i}, & \forall j, \\
W_{l k} \geq 0, \quad \forall l, k, & \\
X_{k j} \geq 0, \quad \forall k, j, & \\
Y_{k i} \geq 0, \forall k, i, & \\
Z_{j i} \geq 0, \forall j, i &
\end{array}
$$

where $0<\alpha_{i}<1$ and $0<\beta_{i}<1$ are the given constants. It is assumed that $W_{l k}, Y_{k i}, X_{k j}$, and $Z_{j i}$ are deterministic and $B_{l}$, and $D_{i}$ are considered as random variables with a known probability distribution. 


\subsection{A probabilistic linearly-constrained approach for FGP-MOSCN with a Pareto distribution}

The Pareto distribution was named after Vilfredo Pareto, a great economist and sociologist. The Pareto distribution is a power law probability distribution that is used in the description of social, scientific, geophysical, actuarial, and many other types of observable phenomena. In this paper, we have assumed both the demand and supply as Pareto random variables. Let us assume that the demand $B_{l}, l=1,2, \ldots, L$ are independent random variables following a Pareto distribution ${ }^{13}$. The probability density function (pdf) of the $l^{\text {th }}$ random variable $B_{l}$ is given by:

$$
f\left(B_{l}\right)= \begin{cases}\frac{p_{l}\left(q_{l}\right)^{p_{l}}}{B_{l}^{\left(p_{l}+1\right)}}, & \text { if } B_{l}>q_{l}, p_{l}>0, q_{l}>0, \\ 0, & \text { if } B_{l} \leq q_{l},\end{cases}
$$

Where $q_{l}$ is the scale parameter, i.e., the minimum possible value of $B_{l}$ and $p_{l}$ is the shape parameters, i.e., a positive parameter which determines the concentration of data towards the mode. Using the shape and scale parameters, the mean $E\left(B_{l}\right)$ and variance $\operatorname{Var}\left(B_{l}\right)$ is calculated as:

$$
\begin{gathered}
E\left(B_{l}\right)=\frac{p_{l} q_{l}}{p_{l}-1}, p_{l}>1, \quad \forall l, \\
\text { and } \operatorname{Var} E\left(B_{l}\right)=\frac{p_{l} q_{l}{ }^{2}}{\left(p_{l}-1\right)^{2}\left(p_{l}-2\right)}, p_{l}>2, \forall l \text {. }
\end{gathered}
$$

Now, using equation (1) and the $i^{\text {th }}$ probability constraint from the problem (3), we get:

$$
\int_{y_{l}}^{\infty} f\left(B_{l}\right) d B_{l} \geq 1-\alpha_{l}, \quad \forall l
$$

where $y_{l}=\sum_{k=1}^{K} W_{l k}$ and $y_{l} \geq 0$.

Now, equation (4) can be written as:

$$
\int_{y_{l}}^{\infty} \frac{p_{l}\left(q_{l}\right)^{p_{l}}}{B_{l}^{\left(p_{l}+1\right)}} d B_{l} \geq 1-\alpha_{l}, \quad \forall l .
$$

For the case when $y_{l} \geq q_{l}$, the above integration model can be calculated as:

$$
\left(\frac{q_{l}}{y_{l}}\right)^{p_{l}} \geq 1-\alpha_{i}, \quad \forall l .
$$

i.e., $y_{l} \leq \frac{q_{l}}{\left(1-\alpha_{l}\right)^{1 / p_{l}}}, \quad \forall l$

i.e., $\quad y_{l}=\sum_{k=1}^{K} W_{l k} \leq \frac{q_{l}}{\left(1-\alpha_{l}\right)^{1 / p_{l}}}, \quad \forall l$.

For the case where $y_{l} \leq q_{l}$, the above integration becomes zero. 
The maximum likelihood estimator for the shape parameter $p_{l}$ is given by:

$$
\hat{p}_{l}=\frac{L}{\sum\left(\operatorname{In} B_{l}-\operatorname{In} \hat{q}_{l}\right)}, \text { where } \hat{q}_{l}=\min _{l} B_{l}
$$

Similarly, for the other supply constraint, we get:

$$
\sum_{j=1}^{J} Z_{j i}+\sum_{k=1}^{K} Y_{k i} \leq \frac{q_{i}}{\left(1-\beta_{i}\right)^{1 / p_{i}}}, \quad \forall i .
$$

The maximum likelihood estimator for the shape parameter $p_{i}$ is given by:

$$
\hat{p}_{i}=\frac{I}{\sum\left(\operatorname{In} D_{i}-\operatorname{In} \hat{q}_{i}\right)}, \text { where } \hat{q}_{i}=\min _{i} D_{i}
$$

Thus, the equivalent FGP problem of the PFGP problem (3) can be stated as:

\section{Problem (4)}

Find $X$ to optimize the following fuzzy goals:

$$
\begin{aligned}
& \sum_{l=1}^{L} \sum_{k=1}^{K} \tilde{C}_{l k} W_{l k}+\sum_{k=1}^{K} \sum_{j=1}^{J} \tilde{C}_{k j} X_{k j}+\sum_{k=1}^{K} \sum_{i=1}^{I} \tilde{C}_{k i} Y_{k i}+\sum_{j=1}^{J} \sum_{i=1}^{I} \tilde{C}_{j i} Z_{j i} \preceq g_{1} \\
& \sum_{k=1}^{K} \sum_{j=1}^{J} \tilde{D}_{k j} X_{k j}+\sum_{k=1}^{K} \sum_{i=1}^{I} \tilde{D}_{k i} Y_{k i}+\sum_{j=1}^{J} \sum_{i=1}^{I} \tilde{D}_{j i} Z_{j i} \preceq g_{2}
\end{aligned}
$$

s.t.

$$
\begin{array}{ll}
\sum_{k=1}^{K} W_{l k} \leq \frac{q_{l}}{\left(1-\alpha_{l}\right)^{1 / p_{l}},} & \forall l, \\
\sum_{i=1}^{I} Y_{k i}+\sum_{j=1}^{J} X_{k j} \leq A_{k}, & \forall k, \\
\sum_{i=1}^{I} Z_{j i} \leq E_{j}, & \forall j, \\
\sum_{j=1}^{J} Z_{j i}+\sum_{k=1}^{K} Y_{k i} \geq \frac{q_{i}}{\left(1-\beta_{i}\right)^{1 / p_{i}}}, & \forall i, \\
\sum_{l=1}^{L} W_{l k} \geq \sum_{j=1}^{J} X_{k j}+\sum_{i=1}^{I} Y_{k i}, & \forall k, \\
\sum_{k=1}^{K} X_{k j} \geq \sum_{i=1}^{I} Z_{j i}, & \\
W_{l k} \geq 0, \forall l, k, & \\
X_{k j} \geq 0, \forall k, j, & \\
Y_{k i} \geq 0, \forall k, i, & \\
Z_{j i} \geq 0, \forall j, i . &
\end{array}
$$


After discussing the fuzzy goal programming and probabilistic fuzzy goal programming formulation of the MOSCN with Pareto distribution, we now proceed to different solution approaches for solving the PFGPMOSCN.

\section{Solution approaches to the PFGP-MOSCN problem with a Pareto distribution}

In this paper, we consider three types of GP, namely, the simple additive goal programming approach, the weighted goal programming approach, and the pre-emptive goal programming approach for solving the deterministic model of the MOSCN.

\subsection{Simple additive approach to the PFGP-MOSCN problem with a Pareto distribution}

Consider the PFGP problem (3), where we assume that the right-hand side variables $B_{l}$, and $D_{i}$ are Pareto random variables, with known mean and variance. The parameters, i.e., the shape $p$ and scale $q$ parameters, are calculated using equations (2) and (3), respectively.

Now, the linear membership functions $\mu_{1}\left(Z_{1}(X)\right)$ and $\mu_{2}\left(Z_{2}(X)\right)$ for the goals are defined according to Zimmemann ${ }^{45}$. For the fuzzy goal type $Z_{1}(X) \preceq g_{1}$, i.e., the fuzzy-min, the linear membership function is defined as:

$$
\mu_{1}\left(Z_{1}(X)\right)= \begin{cases}1, & \text { if } Z_{1}(X) \leq g_{1}, \\ \frac{U_{1}-Z_{1}(X)}{U_{1}-g_{1}}, & \text { if } g_{1} \leq Z_{1}(X) \leq U_{1}, \\ 0, & \text { if } Z_{1}(X) \geq U_{1},\end{cases}
$$

Where $U_{1}$ is the upper tolerance limit. Similarly, for the fuzzy goal type $Z_{2}(X) \preceq g_{2}$, i.e., the fuzzy-min, the linear membership function is defined as:

$$
\mu_{2}\left(Z_{2}(X)\right)= \begin{cases}1, & \text { if } Z_{2}(X) \leq g_{2}, \\ \frac{U_{2}-Z_{2}(X)}{U_{2}-g_{2}}, & \text { if } g_{2} \leq Z_{2}(X) \leq U_{2}, \\ 0, & \text { if } Z_{2}(X) \geq U_{2},\end{cases}
$$

where $U_{2}$ is the upper tolerance limit.

The simple additive model of the PFGP problem (3) is formulated using the linear membership function, as follows: 
Problem (5)

$\operatorname{Max} D(\mu)=\mu_{1}\left(Z_{1}(X)\right)+\mu_{2}\left(Z_{2}(X)\right)$

s.t.

$$
\begin{array}{ll}
\mu_{1}\left(Z_{1}(X)\right)=\frac{U_{1}-Z_{1}(X)}{U_{1}-g_{1}} & \\
\mu_{2}\left(Z_{2}(X)\right)=\frac{U_{2}-Z_{2}(X)}{U_{2}-g_{2}} & \forall l, \\
\operatorname{Pr}\left(\sum_{k=1}^{K} W_{l k} \leq B_{l}\right) \geq 1-\alpha_{l}, & \forall k, \\
\sum_{i=1}^{I} Y_{k i}+\sum_{j=1}^{J} X_{k j} \leq A_{k}, & \forall j, \\
\sum_{i=1}^{I} Z_{j i} \leq E_{j}, & \forall i, \\
\operatorname{Pr}\left(\sum_{j=1}^{J} Z_{j i}+\sum_{k=1}^{K} Y_{k i} \geq D_{i}\right) \geq 1-\beta_{i}, & \\
\sum_{l=1}^{L} W_{l k} \geq \sum_{j=1}^{J} X_{k j}+\sum_{i=1}^{I} Y_{k i}, & \\
\sum_{k=1}^{K} X_{k j} \geq \sum_{i=1}^{I} Z_{j i}, & \\
\mu_{1}\left(Z_{1}(X)\right) \leq 1, & \\
\mu_{2}\left(Z_{2}(X)\right) \leq 1, \\
W_{l k} \geq 0, \forall l, k, \\
X_{k j} \geq 0, \forall k, j, \\
Y_{k i} \geq 0, \forall k, i, \\
Z_{j i} \geq 0, \forall j, i,
\end{array}
$$

where $D(\mu)$ is called a fuzzy achievement function or a fuzzy decision function. This is a single objective optimization problem which can be solved using a suitable classical technique.

\subsection{The weighted additive approach to the PFGP-MOSCN problem with a Pareto distribution}

If the DM is more interested in direct comparisons of the objectives, then the weighted goal programming (WGP) should be used. In the weighted additive approach, weights are attached to each of the objectives to measure the relative importance of the deviations from their target. WGP handles several objectives simultaneously by establishing a specific numeric goal for each of the objectives and then finding a solution that comes close to each of these goals. Popular choices for normalization constants are the range of the corresponding objective (between the best and the worst possible values, hence, mapping all deviations onto a zero-one range). The relative weights may be any real number, where the greater the weight, the greater the assigned importance to minimize the objective function. 
For the fuzzy goal type of fuzzy-min, the equivalent linear model of the PFGP (3) can be written as:

Problem (6)

$$
\begin{aligned}
& \operatorname{Max} D(\mu)=w_{1} \mu_{1}\left(Z_{1}(X)\right)+w_{2} \mu_{2}\left(Z_{2}(X)\right) \\
& \text { s.t. } \\
& \mu_{1}\left(Z_{1}(X)\right)=\frac{U_{1}-Z_{1}(X)}{U_{1}-g_{1}} \\
& \mu_{2}\left(Z_{2}(X)\right)=\frac{U_{2}-Z_{2}(X)}{U_{2}-g_{2}} \\
& \operatorname{Pr}\left(\sum_{k=1}^{K} W_{l k} \leq B_{l}\right) \geq 1-\alpha_{l}, \quad \forall l, \\
& \sum_{i=1}^{I} Y_{k i}+\sum_{j=1}^{J} X_{k j} \leq A_{k}, \quad \forall k, \\
& \sum_{i=1}^{I} Z_{j i} \leq E_{j}, \quad \forall j, \\
& \operatorname{Pr}\left(\sum_{j=1}^{J} Z_{j i}+\sum_{k=1}^{K} Y_{k i} \geq D_{i}\right) \geq 1-\beta_{i}, \quad \forall i, \\
& \sum_{l=1}^{L} W_{l k} \geq \sum_{j=1}^{J} X_{k j}+\sum_{i=1}^{I} Y_{k i}, \quad \forall k, \\
& \sum_{k=1}^{K} X_{k j} \geq \sum_{i=1}^{I} Z_{j i}, \quad \forall j, \\
& \mu_{1}\left(Z_{1}(X)\right) \leq 1 \text {, } \\
& \mu_{2}\left(Z_{2}(X)\right) \leq 1 \text {, } \\
& W_{l k} \geq 0, \forall l, k \text {, } \\
& X_{k j} \geq 0, \quad \forall k, j \text {, } \\
& Y_{k i} \geq 0, \forall k, i \text {, } \\
& Z_{j i} \geq 0, \quad \forall j, i \text {, }
\end{aligned}
$$

where $w_{1}=\frac{1}{u_{1}-g_{1}}$ and $w_{2}=\frac{1}{u_{2}-g_{2}}$ are the relative weights attached to each objective.

\subsection{The pre-emptive goal programming approach to the PFGP-MOSCN problem with a Pareto distribution}

In many situations, a DM may not be able to determine precisely the relative importance of the goals, i.e., to minimize the deviations from the set target values. The basic approach for GP is to set up a specific numeric goal, $g_{k}$, for each objective function, $Z_{k}(X), k=1,2$. Then, the total deviation from the specified goals $\sum_{k=1}^{2}\left|d_{k}\right|$ is minimized, where $d_{k}$ is the deviation from the goal $g_{k}$ for the $k^{\text {th }}$ objective function. To formulate the absolute values, $d_{k}$ can be split into positive and negative parts, such that $d_{k}=d_{k}^{+}-d_{k}^{-}$, with $d_{k}^{+} \geq 0$ and 
$d_{k}^{+}, d_{k}^{-}=0$. Hence, $\left|d_{k}\right|=d_{k}^{+}-d_{k}^{-}$. These negative deviation $d_{k}^{-}$and positive deviation $d_{k}^{+}$are known as under-achievement and over-achievement, respectively, wherein achievement implies that the goal has been achieved..$^{50}$ A pre-emptive GP model of the PFGP problem (3) is formulated as follows:

Problem (7)

$$
\begin{aligned}
& \operatorname{Max} D(\mu)=\left(d_{1}^{-}+d_{1}^{+}\right)+\left(d_{2}^{-}+d_{2}^{+}\right) \\
& \text {s.t. } \\
& \frac{U_{1}-Z_{1}(X)}{U_{1}-g_{1}}+d_{1}^{-}-d_{1}^{+}=1 \\
& \frac{U_{2}-Z_{2}(X)}{U_{2}-g_{2}}+d_{2}^{-}-d_{2}^{+}=1 \\
& \operatorname{Pr}\left(\sum_{k=1}^{K} W_{l k} \leq B_{l}\right) \geq 1-\alpha_{l}, \quad \forall l, \\
& \sum_{i=1}^{I} Y_{k i}+\sum_{j=1}^{J} X_{k j} \leq A_{k}, \quad \forall k, \\
& \sum_{i=1}^{I} Z_{j i} \leq E_{j}, \quad \forall j, \\
& \operatorname{Pr}\left(\sum_{j=1}^{J} Z_{j i}+\sum_{k=1}^{K} Y_{k i} \geq D_{i}\right) \geq 1-\beta_{i}, \quad \forall i, \\
& \sum_{l=1}^{L} W_{l k} \geq \sum_{j=1}^{J} X_{k j}+\sum_{i=1}^{I} Y_{k i}, \quad \forall k, \\
& \sum_{k=1}^{K} X_{k j} \geq \sum_{i=1}^{I} Z_{j i}, \quad \forall j, \\
& W_{l k} \geq 0, \forall l, k \text {, } \\
& X_{k j} \geq 0, \forall k, j, \\
& Y_{k i} \geq 0, \forall k, i, \\
& Z_{j i} \geq 0, \forall j, i, \\
& d_{1}^{-}, d_{2}^{-} \geq 0, d_{1}^{+}, d_{2}^{+} \geq 0, d_{1}^{+} d_{1}^{-}=0 \& d_{2}^{+} d_{2}^{-}=0 \text {. }
\end{aligned}
$$

After discussing the different solution approaches for solving the PFGP-MOSCN, we now consider the hypothetical data for illustrating the solution approaches.

\section{Hypothetical Numerical Example}

In view of illustrating the developed method, we have considered the hypothetical numerical example for modelling and optimization of a Supply Chain Network problem, with some imprecise information considered on it, which is represented by trapezoidal fuzzy numbers. An SCN consists of the manufacturing company with multiple plants, warehouses, retailers, and customers, in different geographical regions or locations. It is assumed that five suppliers supply raw material to four manufacturing plants. The distribution system consists of six 
warehouses, where products are temporarily placed and stored before being sold out to eight retailers, and finally, products are then sold out to several customers. The imprecise data has been summarized in Tables 2-8 below:

Table 2. Fuzzy Transportation Cost from the Supplier to the Plant.

\begin{tabular}{|c|c|c|c|c|}
\hline \multirow[b]{2}{*}{ Supplier } & \multicolumn{4}{|c|}{ Plant } \\
\hline & G1 & G2 & G3 & G4 \\
\hline$\overline{\mathbf{A}}$ & $(195,200,20,15)$ & $(90,100,2,5)$ & $(145,155,2,3)$ & $(120,130,3,6)$ \\
\hline B & $(295,305,5,7)$ & $(145,155,2,3)$ & $(195,200,20,15)$ & $(195,200,20,15)$ \\
\hline C & $(490,500,8,12)$ & $(120,130,3,6)$ & $(203,230,4,5.5)$ & $(203,230,4,5.5)$ \\
\hline D & $(390,405,6.5,7)$ & $(295,305,5,7)$ & $(240,260,2,3)$ & $(27 ., 280,3,5)$ \\
\hline $\mathbf{E}$ & $(590,600,5,4)$ & $(690,705,8,6)$ & $(295,305,5,7)$ & $(340,350,5,7)$ \\
\hline
\end{tabular}

Table 3. Fuzzy Transportation and Production Cost from the Plant to the Retailer.

\begin{tabular}{|c|c|c|c|c|c|c|c|c|}
\hline \multirow[b]{2}{*}{ Plant } & \multicolumn{8}{|c|}{ Retailers } \\
\hline & M1 & M2 & M3 & M4 & M5 & M6 & M7 & M8 \\
\hline G1 & $(295,305,5,7)$ & $(430,450,3,7)$ & $(340,350,5,7)$ & $(430,450,3,7)$ & $(240,260,2,3)$ & $(340,350,5,7)$ & $(390,405,6.5,7)$ & $(470,480,4,6)$ \\
\hline G2 & $(340,350,5,7)$ & $(490,500,8,12)$ & $(295,305,5,7)$ & $(370,380,2,5)$ & $(270,280,3,5)$ & $(370,380,2,5)$ & $(470,480,4,6)$ & $(430,450,3,7)$ \\
\hline G3 & $(430,450,3,7)$ & $(470,480,4,6)$ & $(340,350,5,7)$ & $(340,350,5,7)$ & $(295,305,5,7)$ & $(370,385,5,7)$ & $(430,450,3,7)$ & $470,480,4,6)$ \\
\hline G4 & $(490,500,8,12)$ & $(430,450,3,7)$ & $(320,330,7,8)$ & $(390,405,6.5,7)$ & $((320,330,7,8)$ & $(385,395,4,6)$ & $(420,430,5,6)$ & $(430,450,3,7)$ \\
\hline
\end{tabular}

Table 4. Fuzzy Transportation and Production Cost from the Plant to the Warehouse.

\begin{tabular}{ccccccc}
\hline & \multicolumn{5}{c}{ Warehouses } \\
\cline { 2 - 6 } Plant & N1 & N2 & N3 & N4 & N5 \\
\hline G1 & $(295,305,5,7)$ & $(145,155,2,3)$ & $(195,200,20,15)$ & $(195,200,20,15)$ & $(120,130,3,6)$ \\
G2 & $(390,405,6.5,7)$ & $(120,130,3,6)$ & $(220,230,4,5.5)$ & $(240,260,2,3)$ & $(270,280,3,5)$ & $(310,320,9,6)$ \\
G3 & $(540,550,10,11.5)$ & $(145,155,2,3)$ & $(195,200,20,15)$ & $(295,305,5,7)$ & $(240,260,2,3)$ & $(295,305,5,7)$ \\
G4 & $(640,650,9,13)$ & $(340,350,5,7)$ & $(295,305,5,7)$ & $(170,180,4,6)$ & $(295,305,5,7)$ & $(300,310,3,6)$ \\
\hline
\end{tabular}

Table 5. Fuzzy Transportation Cost from the Warehouses to the Retailer.

\begin{tabular}{|c|c|c|c|c|c|c|c|c|}
\hline \multirow[b]{2}{*}{ Warehouse } & \multicolumn{8}{|c|}{ Retailers } \\
\hline & M1 & M2 & M3 & M4 & M5 & M6 & M7 & M8 \\
\hline N1 & $(145,155,2,3)$ & $(180,190,5,7)$ & $(160,164,8,9)$ & $(170,180,4,6)$ & $(165,175,3,5)$ & $(198,200,6,7)$ & $(183,185,2,5)$ & $(165,175,5,6)$ \\
\hline $\mathbf{N 2}$ & $(110,120,0,3)$ & $(190,210,7,6)$ & $(165,167,3,2)$ & $(165,175,3,5)$ & $(180,190,8,6)$ & $(180,190,8,6)$ & $(184,186,3,4)$ & $(171,173,7,9.5)$ \\
\hline $\mathbf{N 3}$ & $(120,130,3,6)$ & $(90,100,2,5)$ & $(130,132,3.5,4)$ & $(178,179,0,2.5)$ & $(180,190,5,7)$ & $(180,190,5,7)$ & $(183,185,3,3.5)$ & $(170,172,1.5,1)$ \\
\hline N4 & $(128,130,4,3)$ & $(160,170,6,8)$ & $(135,137,2.5,5)$ & $(180,190,8,6)$ & $(190,210,7,6)$ & $(170,180,4,6)$ & $(180,190,5,7)$ & $(170,173,4,5)$ \\
\hline N5 & $(135,140,0,2)$ & $(165,175,3,5)$ & $(145,147,4,3)$ & $(180,190,5,7)$ & $(190,200,5,3)$ & $(160,170,6,8)$ & $(190,210,7,6)$ & $(170,180,4,6)$ \\
\hline N6 & $(170,180,4,6)$ & $(150,160,3,6)$ & $(145,155,2,3)$ & $(90,100,2,5)$ & $(195,200,6,7))$ & $(180,190,8,6)$ & $(190,200,5,3)$ & $(165,175,5,6)$ \\
\hline
\end{tabular}

Table 6. Fuzzy Delivery Time of Item from the Plant to the Retailer.

\begin{tabular}{ccccccccc}
\hline & \multicolumn{9}{c}{ Retailers } \\
\cline { 2 - 8 } Plant & M1 & M2 & M3 & M4 & M5 & M6 & M7 & M8 \\
\hline G1 & $(45,50,0,1)$ & $(65,75,2,4)$ & $(50,60,0,2)$ & $(60,70,3,4)$ & $(35,45,0,1)$ & $(48,50,1,2)$ & $(70,80,2.5,3)$ & $(75,85,3,4)$ \\
G2 & $(30,40,0,1)$ & $(55,653,2)$ & $(40,50,5.5,8)$ & $(35,45,0,1)$ & $(20,30,0,1.5)$ & $(48,50,1,2)$ & $(65,75,2,4)$ & $(75,85,3,4)$ \\
G3 & $(70,80,2.5,3)$ & $(65,75,2,4)$ & $(70,75,5,3)$ & $(75,85,3,4)$ & $(55,653,2)$ & $(65,75,2,4)$ & $(70,80,2,3)$ & $(90,95,3,4)$ \\
G4 & $(90,95,3,4)$ & $(90,100,3,7)$ & $(75,85,3,4)$ & $(80,90,4,6)$ & $(55,653,2)$ & $(65,75,2,4)$ & $(75,80,1.5,2)$ & $(65,70,2,4)$ \\
\hline
\end{tabular}

Table 7. Fuzzy Delivery Time of Item from the Plant to the Warehouse.

\begin{tabular}{ccccccc}
\hline & \multicolumn{5}{c}{ Warehouses } \\
\cline { 2 - 6 } Plant & N1 & N2 & N3 & N4 & N5 \\
\hline G1 & $(25,35,0,2)$ & $(15,25,0,1)$ & $(15,25,0,1)$ & $(10,15,0,2)$ & $(25,30,2,3)$ & $(25,28,2,4)$ \\
G2 & $(35,45,0,1)$ & $(15,25,0,1)$ & $(20,30,0,1.5)$ & $(25,30,2,3)$ & $(25,28,2,4)$ & $(35,40,3.2)$ \\
G3 & $(50,60,0,2)$ & $(55,653,2)$ & $(50,60,5,3)$ & $(55,60,5,3)$ & $(55,653,2)$ & $(35,45,0,1)$ \\
G4 & $(80,90,4,6)$ & $(55,653,2)$ & $(40,50,5.5,8)$ & $(40,50,5.5,8)$ & $(65,75,2,4)$ & $(70,80,2.5,3)$ \\
\hline
\end{tabular}


Table 8. Fuzzy Delivery Time of Item from the Warehouse to the Retailer.

\begin{tabular}{ccccccccc}
\hline \multirow{2}{*}{ Warehouses } & \multicolumn{9}{c}{ Retailers } \\
\cline { 2 - 8 } & M1 & M2 & M3 & M4 & M5 & M6 & M7 & M8 \\
\hline N1 & $(15,25,0,1)$ & $(15,19,0,1)$ & $(20,30,0,1.5)$ & $(25,35,0,2)$ & $(20,30,0,1.5)$ & $(20,30,0,1.5)$ & $(30,40,0,1)$ & $(30,32,5,0)$ \\
N2 & $(20,21,0,2)$ & $(15,25,0,2)$ & $(20,30,0,1.5)$ & $(20,20,0,3)$ & $(27,29,2,4)$ & $(27,29,2,4)$ & $(30,40,0,1)$ & $(25,28,2,4)$ \\
N3 & $(20,30,0,1.5)$ & $(15,25,0,1)$ & $(20,21,0,2)$ & $(30,40,0,1)$ & $(30,33,2,0)$ & $(35,45,0,1)$ & $(40,42,2,4)$ & $(35,40,3,2)$ \\
N4 & $(15,25,0,1)$ & $(20,22,0,3)$ & $(20,22,0,3)$ & $(25,28,2,4)$ & $(27,29,2,4)$ & $(26,28,4,3)$ & $(22,24,0.5,3)$ & $(20,22,0,3)$ \\
N5 & $(15,25,0,1)$ & $(16,18,0,1)$ & $(15,17,2,0)$ & $(14,16,3,2)$ & $(35,40,3,2)$ & $(34,36,2,4)$ & $(36,38,5,6)$ & $(40,42,2,4)$ \\
N6 & $(14,16,3,2)$ & $(10,15,0,2)$ & $(15,17,2,0)$ & $(16,18,0,1)$ & $(30,32,5,0)$ & $(29,31,4,5)$ & $(40,42,2,4)$ & $(68,72,0,4)$ \\
\hline
\end{tabular}

Assume that the potential capacities of these 4 plants are 471,296,327, and 318 units, respectively. Similarly, the potential capacities of these 6 warehouses are 154,177,160,202,178, and 218 units, respectively. The overall cost for transporting the product from the supplier to the plant is $(195,200,20,15)$, i.e., the transportation cost is more likely to increase from 195 to 200 but less likely to increase from 200 to 215 or decrease from 195 to 175 . Similarly, the overall time for transporting the product from the plant to the retailer is $(65,75,2,4)$, i.e., the delivery time is more likely to increase from 65 to 75 , but less likely to increase from 75 to 79 or decrease from 65 to 63 .

By using the above information, the problem can be formulated as a multi-objective probabilistic linearlyconstrained programming problem, as follows:

\section{Problem (8)}

Minimize $Z_{1}=(195,200,20,15) W_{11}+(90,100,2,5) W_{12}+\ldots+(295,305,5,7) W_{53}+(340,350,5,7) W_{54}$

$$
\begin{aligned}
+ & (295,305,5,7) X_{11}+(145,155,2,3) X_{12}+\ldots+(295,305,5,7) X_{45}+(300,310,3,6) X_{46} \\
& +(295,305,5,7) Y_{11}+(430,450,3,7) Y_{12}+\ldots+(420,430,5,6) Y_{47}+(430,450,3,7) Y_{48} \\
& +(145,155,2,3) Z_{11}+(180,190,5,7) Z_{12}+\ldots+(190,200,5,3) Z_{67}+(165,175,5,6) Z_{68} ; \\
\text { Minimize } & Z_{2}=(25,35,0,2) X_{11}+(15,25,0,1) X_{12}+\ldots+(65,75,2,4) X_{45}+(70,80,2.5,3) X_{46}
\end{aligned}
$$$$
+(45,50,0,1) Y_{11}+(65,75,2,4) Y_{12}+\ldots+(75,80,1.5,2) Y_{47}+(65,70,2,4) Y_{48}
$$$$
+(15,25,0,1) Z_{11}+(15,19,0,1) Z_{12}+\ldots+(40,42,2,4) Z_{67}+(68,72,0,4) Z_{68} ;
$$

s.t.

$$
\begin{array}{ll}
\operatorname{Pr}\left(\sum_{k=1}^{4} W_{l k} \leq B_{l}\right) \geq 1-\alpha_{l}, & l=1,2,3,4,5, \\
\sum_{i=1}^{8} Y_{k i}+\sum_{j=1}^{6} X_{k j} \leq A_{k}, & k=1,2,3,4, \\
\sum_{i=1}^{8} Z_{j i} \leq E_{j}, & j=1,2, \ldots, 6, \\
\operatorname{Pr}\left(\sum_{j=1}^{6} Z_{j i}+\sum_{k=1}^{4} Y_{k i} \geq D_{i}\right) \geq 1-\beta_{i}, & i=1,2, \ldots, 8, \\
\sum_{l=1}^{5} W_{l k} \geq \sum_{j=1}^{6} X_{k j}+\sum_{i=1}^{8} Y_{k i}, & k=1,2,3,4, \\
\sum_{k=1}^{4} X_{k j} \geq \sum_{i=1}^{8} Z_{j i}, &
\end{array}
$$


where $\alpha^{\prime} s$ and $\beta^{\prime} s$ are the specified probability levels decided by DM. Also, the DM assumes that $W_{l k}, Y_{k i}, X_{k j}$, and $Z_{j i}$ are deterministic in the model, and the right-hand side variables $B_{l}$, and $D_{i}$ are Pareto random variables, respectively. Using Wolfram Mathematica 9.0, the maximum likelihood parameter estimates, assuming a Pareto distribution for different datasets are given below in Table (8).Using the maximum likelihood estimation on data set $B_{1}$, the Pareto probability density function for the shape parameter $p_{1}=90.247$ and scale parameter $q_{l}=179$. The mean and variance of the respective data set $B_{l}$ is calculated using equations (2) and (3).The deterministic value of the right-hand side variable is calculated using equation (5). Other assumed random variables with their shape and scale parameters are illustrated in Table 9.

Table 9. Pareto Distribution Parameters.

\begin{tabular}{cccccccc}
\hline $\begin{array}{c}\text { RHS } \\
\text { Variable }\end{array}$ & \multicolumn{1}{c}{ Data Sets } & Probability & Shape & Scale & Mean & Variance & $\begin{array}{c}\text { RHS } \\
\text { Value }\end{array}$ \\
\hline$B_{1}$ & $179,180,181,182,183$ & $\alpha_{1}=0.90$ & 90.247 & 179 & 181.01 & 4.1139 & $\mathbf{1 8 4}$ \\
$B_{2}$ & $475,476,477,478,479$ & $\alpha_{2}=0.91$ & 238.25 & 475 & 477.0 & 4.0424 & $\mathbf{4 8 0}$ \\
$B_{3}$ & $195,196,197,198,199$ & $\alpha_{3}=0.92$ & 98.247 & 195 & 197.01 & 4.1044 & $\mathbf{2 0 0}$ \\
$B_{4}$ & $197,198,199,200,201$ & $\alpha_{4}=0.89$ & 99.247 & 197 & 199.01 & 4.1033 & $\mathbf{2 0 1}$ \\
$B_{5}$ & $292,293,294,295,296$ & $\alpha_{5}=0.88$ & 146.75 & 292 & 294.0 & 4.0693 & $\mathbf{2 9 6}$ \\
$D_{1}$ & $90,91,92,93,94$ & $\beta_{1}=0.75$ & 45.744 & 90 & 92.011 & 4.2309 & $\mathbf{9 3}$ \\
$D_{2}$ & $50,51,52,53,54$ & $\beta_{2}=0.76$ & 25.74 & 50 & 52.021 & 4.4288 & $\mathbf{5 3}$ \\
$D_{3}$ & $86,87,88,89,90$ & $\beta_{3}=0.77$ & 43.744 & 86 & 88.012 & 4.2420 & $\mathbf{8 9}$ \\
$D_{4}$ & $62,63,64,65,66$ & $\beta_{4}=0.78$ & 31.742 & 62 & 64.017 & 4.3411 & $\mathbf{6 5}$ \\
$D_{5}$ & $60,61,62,63,64$ & $\beta_{5}=0.79$ & 30.741 & 60 & 62.0 & 4.3531 & $\mathbf{6 3}$ \\
$D_{6}$ & $107,108,109,110,111,112$ & $\beta_{6}=0.74$ & 54.245 & 107 & 109.01 & 4.1930 & $\mathbf{1 1 0}$ \\
$D_{7}$ & $108,109,110,111,112$ & $\beta_{7}=0.73$ & 54.745 & 108 & 110.0 & 4.1912 & $\mathbf{1 1 1}$ \\
$D_{8}$ & $78,79,80,81,82$ & $\beta_{8}=0.72$ & 39.743 & 78 & 80.013 & 4.2680 & $\mathbf{8 1}$ \\
\hline
\end{tabular}

By using the above information, the problem can be formulated as a multi-objective probabilistic linearly-constrained GP problem, as follows:

\section{Problem (9)}

$$
\begin{aligned}
& Z_{1}=\left\{\begin{array}{c}
197.083 W_{11}+95.250 W_{12}+\ldots+300.167 W_{53}+345.167 W_{54} \\
+300.167 X_{11}+15.083 X_{12}+\ldots+300.167 X_{45}+305.250 X_{46} \\
+300.167 Y_{11}+440.337 Y_{12}+\cdot \cdot+425.083 Y_{47}+444.333 Y_{48} \\
+150.083 Z_{11}+185.167 Z_{12}+\ldots+194.833 Z_{67}+170.167 Z_{68}
\end{array}\right\} \preceq 278983.5 \\
& Z_{2}=\left\{\begin{aligned}
& 30.167 X_{11}+20.083 X_{12}+\ldots+70.167 X_{45}+75.042 X_{46} \\
&+ 47.583 Y_{11}+70.167 Y_{12}+\ldots+77.542 Y_{47}+67.667 Y_{48} \\
&+20.083 Z_{11}+17.083 Z_{12}+\ldots+42.667 Z_{67}+70.333 Z_{68}
\end{aligned}\right\} \preceq 25325.72
\end{aligned}
$$




$$
\begin{array}{lr}
\text { s.t. } & l=1,2,3,4,5, \\
\sum_{k=1}^{4} W_{l k} \leq B_{l}, & k=1,2,3,4, \\
\sum_{i=1}^{8} Y_{k i}+\sum_{j=1}^{6} X_{k j} \leq A_{k}, & j=1,2, \ldots, 6, \\
\sum_{i=1}^{8} Z_{j i} \leq E_{j}, & i=1,2, \ldots, 8, \\
\sum_{j=1}^{6} Z_{j i}+\sum_{k=1}^{4} Y_{k i} \geq D_{i}, & k=1,2,3,4, \\
\sum_{l=1}^{5} W_{l k} \geq \sum_{j=1}^{6} X_{k j}+\sum_{i=1}^{8} Y_{k i}, & j=1,2, \ldots, 6, \\
\sum_{k=1}^{4} X_{k j} \geq \sum_{i=1}^{8} Z_{j i}, &
\end{array}
$$

Suppose that the upper tolerance limit for the transportation cost and delivery time are determined by the DM as 12,64,694 and 1,29,890.1Indian rupees, respectively, while the lower tolerance limits for the transportation cost and delivery time are 2,78,983.5 and 25,325.72 Indian rupees, respectively. Under these circumstances, the fuzzy-min type of the linear membership functions $\mu_{1}\left(Z_{1}(X)\right)$ and $\mu_{2}\left(Z_{2}(X)\right)$ is defined forthe transportation cost and delivery time, respectively, as follows:

$$
\begin{aligned}
& \mu_{1}\left(Z_{1}(X)\right)= \begin{cases}1, & \text { if } Z_{1}(X) \leq 278983.5, \\
\frac{1264694-Z_{1}(X)}{1264694-278983.5}, & \text { if } 278983.5 \leq Z_{1}(X) \leq 1264694, \\
0, & \text { if } Z_{1}(X) \geq 1264694,\end{cases} \\
& \mu_{2}\left(Z_{2}(X)\right)= \begin{cases}1, & \text { if } Z_{2}(X) \leq 25325.72, \\
\frac{129890.1-Z_{2}(X)}{129890.1-25325.72}, & \text { if } 25325.72 \leq Z_{2}(X) \leq 129890.1, \\
0, & \text { if } Z_{2}(X) \geq 129890.1,\end{cases}
\end{aligned}
$$

Using a simple additive approach, the deterministic equivalent linear mathematical model of the PFGP can be formulated as:

$$
\begin{array}{ll}
\operatorname{Max} & D(\mu)=\mu_{1}\left(Z_{1}(X)\right)+\mu_{2}\left(Z_{2}(X)\right) \\
\text { s.t. } & \\
& \mu_{1}\left(Z_{1}(X)\right)=\frac{1264694-Z_{1}(X)}{1264694-278983.5}, \\
& \mu_{2}\left(Z_{2}(X)\right)=\frac{129890.1-Z_{2}(X)}{129890.1-25325.72}, \\
& \mu_{1}\left(Z_{1}(X)\right) \leq 1, \mu_{2}\left(Z_{2}(X)\right) \leq 1, \\
& \mu_{1}\left(Z_{1}(X)\right) \geq 0, \mu_{2}\left(Z_{2}(X)\right) \geq 0,
\end{array}
$$


and the set of constraints of Problem (9).

In this case, we have considered a situation where in specific parameters of the MOSCN problem are not fixed or known. In such cases, the quantities are considered to be random variables. To overcome this uncertainty, we have considered that the supply and demand parameters of the constraints follow a Pareto distribution. After converting the probabilistic constraints into deterministic ones, the above-formulated problem is solved by using the optimization software LINGO16.0, and we get the following compromise solution for the quantity shipped from the supply source to the plant, quantity shipped from the plant to the warehouse, quantity shipped from the plant to the retailer, and quantity shipped from the warehouse to the retailer:

$$
\begin{gathered}
W_{14}=184, W_{22}=273, W_{24}=80, W_{32}=200, W_{42}=108, X_{22}=177, X_{23}=53, X_{44}=192, Y_{21}=91, \\
Y_{23}=89, Y_{25}=63, Z_{21}=2, Z_{24}=65, Z_{26}=110, Z_{32}=53, Z_{47}=111, Z_{48}=81
\end{gathered}
$$

The DM accepts this solution and considers it as the preferred compromise solution with achieved goal value of $Z_{1}=282788.3$, and $Z_{2}=27479.3$. The value of the membership function related to the goalis found to be $\mu_{1}\left(Z_{1}(X)\right)=0.9961401$, and $\mu_{2}\left(Z_{2}(X)\right)=0.9794068$, which implies that the DM has reached the satisfaction level of $99 \%$ and $97 \%$ for the respective objective functions.

Similarly, the relative weights of the two objective functions considered by the DM are $w_{1}=0.000001014$ and $w_{2}=0.000009563$.Then, using a weighted additive approach, the deterministic equivalent linear mathematical model of the PFGP can be obtained as:

$$
\operatorname{Max} D(\mu)=0.000001014 \mu_{1}\left(Z_{1}(X)\right)+0.000009563 \mu_{2}\left(Z_{2}(X)\right)
$$

s.t.

$$
\begin{aligned}
& \mu_{1}\left(Z_{1}(X)\right)=\frac{1264694-Z_{1}(X)}{1264694-278983.5} \\
& \mu_{2}\left(Z_{2}(X)\right)=\frac{129890.1-Z_{2}(X)}{129890.1-25325.72}, \\
& \mu_{1}\left(Z_{1}(X)\right) \leq 1, \mu_{2}\left(Z_{2}(X)\right) \leq 1 \\
& \mu_{1}\left(Z_{1}(X)\right) \geq 0, \mu_{2}\left(Z_{2}(X)\right) \geq 0
\end{aligned}
$$

and the set of constraints of Problem (9).

After converting the probabilistic constraints into deterministic ones, the above-formulated problem is solved by using the optimization software LINGO16.0, and we get the following compromise solution for the quantity shipped from the supply source to the plant, quantity shipped from the plant to the warehouse, quantity shipped from the plant to the retailer, and quantity shipped from the warehouse to the retailer:

$$
\begin{aligned}
& W_{21}=138, W_{13}=46, W_{23}=80, W_{32}=200, W_{43}=201, X_{22}=42, X_{25}=178, Y_{21}=55, Y_{25}=63, \\
& Y_{33}=29, Y_{36}=110, Y_{37}=111, Y_{38}=77, Z_{21}=38, Z_{28}=40, Z_{52}=53, Z_{53}=60, Z_{54}=65
\end{aligned}
$$


The DM accepts this solution and considers it as the preferred compromise solution with achieved goal value of $Z_{1}=368301.50$, and $Z_{2}=38185.27$. The value of the membership function related to the goalis found to be $\mu_{1}\left(Z_{1}(X)\right)=0.9093872$, and $\mu_{2}\left(Z_{2}(X)\right)=0.8770178$, which implies that the DM has reached the satisfaction level of $91 \%$ and $88 \%$ for the respective objective functions.

Using the pre-emptive GP approach, the deterministic equivalent linear mathematical model of the PFGP can be formulated as:

$$
\begin{aligned}
& \text { Min } D(\mu)=\left(d_{1}^{+}+d_{1}^{-}\right)+\left(d_{2}^{+}+d_{2}^{-}\right) \\
& \text {s.t. } \\
& \begin{array}{c}
\frac{1264694-Z_{1}(X)}{1264694-278983.5}+d_{1}^{+}-d_{1}^{-}=1, \\
\frac{129890.1-Z_{2}(X)}{129890.1-25325.72}+d_{2}^{+}-d_{2}^{-}=1,
\end{array} \\
& d_{1}^{-}, d_{2}^{-} \geq 0, d_{1}^{+}, d_{2}^{+} \geq 0, d_{1}^{+} d_{1}^{-}=0 \& d_{2}^{+} d_{2}^{-}=0, \\
& \text { and the set of constraints of Problem (9) }
\end{aligned}
$$

After converting the probabilistic constraints into deterministic ones, the above-formulated problem is solved by using the optimization software LINGO16.0, and we get the following compromise solution for the quantity shipped from the supply source to the plant, quantity shipped from the plant to the warehouse, quantity shipped from the plant to the retailer, quantity shipped from the warehouse to the retailer:

$$
\begin{aligned}
& W_{14}=184, W_{22}=273, W_{24}=80, W_{32}=200, X_{22}=177, X_{23}=54, X_{44}=192, Y_{21}=91, Y_{23}=89, \\
& Y_{25}=63, Z_{21}=20, Z_{24}=65, Z_{26}=110, Z_{32}=53, Z_{47}=111, Z_{48}=81
\end{aligned}
$$

The DM accepts this solution and considers it as the preferred compromise solution with achieved goal value of $Z_{1}=282788.30$, and $Z_{2}=27479.04$. The value of the deviation related to the goalis found to be $d_{1}=d_{1}^{+}-d_{1}^{-}=0.00385993$, and $d_{2}=d_{2}^{+}-d_{2}^{-}=0.02059322$.Fig. 2 provides a graphical representation of Methods 1, 2, and 3. Furthermore, the sensitivity analysis of all decision variables of the MOSCN model are shown in Table 10. 


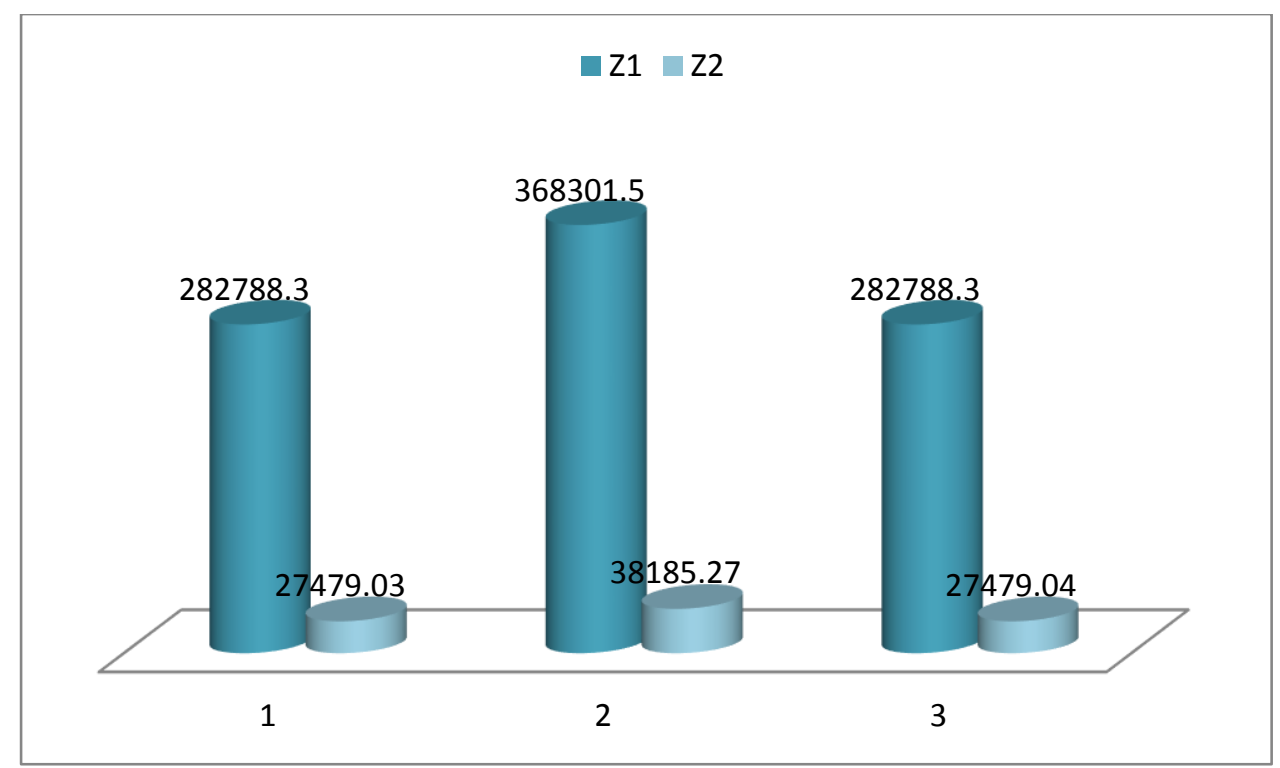

Fig 2.Graphical Representation of Method1, Method 2, and Method 3.

Table 10. Sensitivity Analysis of the Decision Variables.

\begin{tabular}{|c|c|c|c|}
\hline $\begin{array}{c}W_{11} \\
(197.08,197.08+\infty)\end{array}$ & $\begin{array}{c}W_{12} \\
(95,95+\infty)\end{array}$ & $\begin{array}{c}W_{13} \\
(150.08,347.16)\end{array}$ & $\begin{array}{c}W_{14} \\
(103.34,322.33) \\
\end{array}$ \\
\hline $\begin{array}{c}W_{21} \\
(300.17,300.17+\infty)\end{array}$ & $\begin{array}{c}W_{22} \\
(150.08,150.08+\infty)\end{array}$ & $\begin{array}{c}W_{23} \\
(47,197.08+\infty) \\
\end{array}$ & $\begin{array}{c}W_{24} \\
(71.83,197.08+\infty)\end{array}$ \\
\hline $\begin{array}{c}W_{31} \\
(495.33,495.33+\infty)\end{array}$ & $\begin{array}{c}W_{32} \\
(125.25,125.25+\infty)\end{array}$ & $\begin{array}{c}W_{33} \\
(75.05,225.13+\infty)\end{array}$ & $\begin{array}{c}W_{34} \\
(99.88,225.13+\infty)\end{array}$ \\
\hline $\begin{array}{c}W_{41} \\
(397.04,397.04+\infty)\end{array}$ & $\begin{array}{c}W_{42} \\
(300.17,300.17+\infty)\end{array}$ & $\begin{array}{c}W_{43} \\
(100,250.08+\infty) \\
\end{array}$ & $\begin{array}{c}W_{44} \\
(149.92,275.17+\infty)\end{array}$ \\
\hline $\begin{array}{c}W_{51} \\
(595.92,595.92+\infty)\end{array}$ & $\begin{array}{c}W_{52} \\
(696.83,696.83+\infty)\end{array}$ & $\begin{array}{c}W_{53} \\
(150.09,300.17+\infty)\end{array}$ & $\begin{array}{c}W_{54} \\
(219.92,345.17+\infty)\end{array}$ \\
\hline $\begin{array}{c}X_{11} \\
(191.08,697.21)\end{array}$ & $\begin{array}{c}X_{12} \\
(44.83,150.08+\infty)\end{array}$ & $\begin{array}{c}X_{13} \\
(56.95,397.25)\end{array}$ & $\begin{array}{c}X_{14} \\
(62.12,447.16)\end{array}$ \\
\hline $\begin{array}{c}X_{15} \\
(30.17,270.50)\end{array}$ & $\begin{array}{c}X_{16} \\
(120,614.92)\end{array}$ & $\begin{array}{c}X_{21} \\
(96.87,397.04+\infty)\end{array}$ & $\begin{array}{c}X_{22} \\
(20.00,125.25+\infty)\end{array}$ \\
\hline $\begin{array}{c}X_{23} \\
(28.05,225.13+\infty) \\
\end{array}$ & $\begin{array}{c}X_{24} \\
(53,250.08+\infty) \\
\end{array}$ & $\begin{array}{c}X_{25} \\
(149.92,275.17+\infty)\end{array}$ & $\begin{array}{c}X_{26} \\
(14.52,314.75+\infty)\end{array}$ \\
\hline $\begin{array}{c}X_{31} \\
(395.04,545.13+\infty)\end{array}$ & $\begin{array}{c}X_{32} \\
(194.91,150.08+\infty)\end{array}$ & $\begin{array}{c}X_{33} \\
(150.08,197.08+\infty)\end{array}$ & $\begin{array}{c}X_{34} \\
(253.17,300.17+\infty)\end{array}$ \\
\hline $\begin{array}{c}X_{35} \\
(274.91,250.08+\infty)\end{array}$ & $\begin{array}{c}X_{36} \\
(150.08,300.17+\infty)\end{array}$ & $\begin{array}{c}X_{41} \\
(465.41,640.33+\infty) \\
\end{array}$ & $\begin{array}{c}X_{42} \\
(365.17,345.17+\infty) \\
\end{array}$ \\
\hline $\begin{array}{c}X_{43} \\
(228.34,300.17+\infty)\end{array}$ & $\begin{array}{c}X_{44} \\
(103.34,175.17+\infty)\end{array}$ & $\begin{array}{c}X_{45} \\
(300.17,300.17+\infty)\end{array}$ & $\begin{array}{c}X_{46} \\
(130.33,305.25+\infty)\end{array}$ \\
\hline $\begin{array}{c}Y_{11} \\
(79.67,300.17+\infty)\end{array}$ & $\begin{array}{c}Y_{12} \\
(148.09,440.34+\infty)\end{array}$ & $\begin{array}{c}Y_{13} \\
(74,345.17+\infty)\end{array}$ & $\begin{array}{c}Y_{14} \\
(164.91,440.33+\infty)\end{array}$ \\
\hline $\begin{array}{c}Y_{15} \\
(0,525.25)\end{array}$ & $\begin{array}{c}Y_{16} \\
(55.09,345.17+\infty)\end{array}$ & $\begin{array}{c}Y_{17} \\
(106.71,397.04+\infty)\end{array}$ & $\begin{array}{c}Y_{18} \\
(197.71,475.17+\infty)\end{array}$ \\
\hline
\end{tabular}




\begin{tabular}{|c|c|c|c|}
\hline $\begin{array}{c}Y_{21} \\
(124.67,345.17+\infty)\end{array}$ & $\begin{array}{c}Y_{22} \\
(203.08,495.33+\infty)\end{array}$ & $\begin{array}{c}Y_{23} \\
(29,300.17+\infty) \\
\end{array}$ & $\begin{array}{c}Y_{24} \\
(99.83,375.25+\infty) \\
\end{array}$ \\
\hline $\begin{array}{c}Y_{25} \\
(25.09,275.17+\infty) \\
\end{array}$ & $\begin{array}{c}Y_{26} \\
(85.17,375.25+\infty) \\
\end{array}$ & $\begin{array}{c}Y_{27} \\
(184.84,475.17+\infty)\end{array}$ & $\begin{array}{c}Y_{28} \\
(590.41,440.33+\infty)\end{array}$ \\
\hline $\begin{array}{c}Y_{31} \\
(369.91,440.33+\infty)\end{array}$ & $\begin{array}{c}Y_{32} \\
(333,475.17+\infty) \\
\end{array}$ & $\begin{array}{c}Y_{33} \\
(224.08,345.17+\infty)\end{array}$ & $\begin{array}{c}Y_{34} \\
(219.83,345.17+\infty)\end{array}$ \\
\hline $\begin{array}{c}Y_{35} \\
(200.17,300.17+\infty)\end{array}$ & $\begin{array}{c}Y_{36} \\
(237.17,377.17+\infty)\end{array}$ & $\begin{array}{c}Y_{37} \\
(300.08,440.33+\infty)\end{array}$ & $\begin{array}{c}Y_{38} \\
(530,475.17+\infty)\end{array}$ \\
\hline $\begin{array}{c}Y_{41} \\
(620.58,495.33+\infty)\end{array}$ & $\begin{array}{c}Y_{42} \\
(273.33,440.33+\infty)\end{array}$ & $\begin{array}{c}Y_{43} \\
(179.16,325.08+\infty)\end{array}$ & $\begin{array}{c}Y_{44} \\
(246.87,397.04+\infty)\end{array}$ \\
\hline $\begin{array}{c}Y_{45} \\
(200.25,325.08+\infty)\end{array}$ & $\begin{array}{c}Y_{46} \\
(225.30,390.13+\infty)\end{array}$ & $\begin{array}{c}Y_{47} \\
(260,425.08+\infty)\end{array}$ & $\begin{array}{c}Y_{48} \\
(292.12,150.08+\infty)\end{array}$ \\
\hline $\begin{array}{c}Z_{11} \\
(229.75,150.08+\infty)\end{array}$ & $\begin{array}{c}Z_{12} \\
(193.09,185.17+\infty)\end{array}$ & $\begin{array}{c}Z_{13} \\
(191.08,162.08+\infty)\end{array}$ & $\begin{array}{c}Z_{14} \\
(199.92,175.17+\infty)\end{array}$ \\
\hline $\begin{array}{c}Z_{15} \\
(220.26,170.17+\infty) \\
\end{array}$ & $\begin{array}{c}Z_{16} \\
(209.92,199.83+\infty)\end{array}$ & $\begin{array}{c}Z_{17} \\
(194.10,184.26+\infty)\end{array}$ & $\begin{array}{c}Z_{18} \\
(192.79,170.08+\infty)\end{array}$ \\
\hline $\begin{array}{c}Z_{21} \\
(220.50,272.92+\infty)\end{array}$ & $\begin{array}{c}Z_{22} \\
(12.20,199.20+\infty)\end{array}$ & $\begin{array}{c}Z_{23} \\
(0,344.04) \\
\end{array}$ & $\begin{array}{c}Z_{24} \\
(275.42,375.79) \\
\end{array}$ \\
\hline $\begin{array}{c}Z_{25} \\
(40,184.83+\infty) \\
\end{array}$ & $\begin{array}{c}Z_{26} \\
(290.33,370.00) \\
\end{array}$ & $\begin{array}{c}Z_{27} \\
(290.33,405.00) \\
\end{array}$ & $\begin{array}{c}Z_{28} \\
(27746,3967.38) \\
\end{array}$ \\
\hline $\begin{array}{c}Z_{31} \\
(101.83,125.25+\infty)\end{array}$ & $\begin{array}{c}Z_{32} \\
(193.51,292.25) \\
\end{array}$ & $\begin{array}{c}Z_{33} \\
(56.95,131.04+\infty)\end{array}$ & $\begin{array}{c}Z_{34} \\
(100.37,178.71+\infty)\end{array}$ \\
\hline $\begin{array}{c}Z_{35} \\
(132.17,185.17+\infty)\end{array}$ & $\begin{array}{c}Z_{36} \\
(92.17,185.17+\infty)\end{array}$ & $\begin{array}{c}Z_{37} \\
(90.79,184.04+\infty)\end{array}$ & $\begin{array}{c}Z_{38} \\
(90.58,170.96+\infty)\end{array}$ \\
\hline $\begin{array}{c}Z_{41} \\
(105.50,128.92+\infty)\end{array}$ & $\begin{array}{c}Z_{42} \\
(70,165.17+\infty)\end{array}$ & $\begin{array}{c}Z_{43} \\
(62.12,136.21+\infty)\end{array}$ & $\begin{array}{c}Z_{44} \\
(106.49,184.83+\infty)\end{array}$ \\
\hline $\begin{array}{c}Z_{45} \\
(146.92,199.92+\infty)\end{array}$ & $\begin{array}{c}Z_{46} \\
(82.17,175.17+\infty)\end{array}$ & $\begin{array}{c}Z_{47} \\
(91.92,185.17+\infty)\end{array}$ & $\begin{array}{c}Z_{48} \\
(91.20,171.58+\infty)\end{array}$ \\
\hline $\begin{array}{c}Z_{51} \\
(42.42,137.67+\infty) \\
\end{array}$ & $\begin{array}{c}Z_{52} \\
(30.17,170.17+\infty)\end{array}$ & $\begin{array}{c}Z_{53} \\
(12.20,292.18+\infty)\end{array}$ & $\begin{array}{c}Z_{54} \\
(35.45,185.62+\infty)\end{array}$ \\
\hline $\begin{array}{c}Z_{55} \\
(70.00,194.83+\infty)\end{array}$ & $\begin{array}{c}Z_{56} \\
(40.00,165.17+\infty)\end{array}$ & $\begin{array}{c}Z_{57} \\
(34.84,199.92+\infty)\end{array}$ & $\begin{array}{c}Z_{58} \\
(22.96,175.17+\infty)\end{array}$ \\
\hline $\begin{array}{c}Z_{61} \\
(254.84,175.17+\infty)\end{array}$ & $\begin{array}{c}Z_{62} \\
(164.17,158.25+\infty)\end{array}$ & $\begin{array}{c}Z_{63} \\
(179.08,95.25+\infty)\end{array}$ & $\begin{array}{c}Z_{64} \\
(120.00,197.58+\infty)\end{array}$ \\
\hline $\begin{array}{c}Z_{65} \\
(247.67,197.58+\infty)\end{array}$ & $\begin{array}{c}Z_{66} \\
(194.92,184.83+\infty)\end{array}$ & $\begin{array}{c}Z_{67} \\
(204.67,194.83 .+\infty)\end{array}$ & $\begin{array}{c}Z_{68} \\
(192.88,170.17+\infty)\end{array}$ \\
\hline
\end{tabular}

\section{Managerial Insights and Contribution, Limitations, and Future Scope}

The proposed MOSCN model considersproduct demand-and supply-rooted uncertainty and, hence, provides flexibility to optimise the cost related to SCN under ambiguity. Furthermore, the model is built considering fuzziness and probabilistic situations, which may be of help to managers in tackling the different situations of ambiguity and randomness.

The proposed MOSCN model makes the following contributions: (1) a new mathematical model for SCN is formulated, with the primary objective of minimizing the transportation cost and delivery time; (2) the proposed work links fuzziness in transportation cost and delivery time with randomness in demand and supply parameters; 
(c) the developed parameters follow a Paretodistribution, whichis consideredto be the best distribution in risk analysis; and (d) three different additive approaches, namely simple, weighted, and pre-emptive, are used to solve the probabilistic fuzzy goal programming model.

As for the limitations of the current study, these mainly have to do with the fact that the case study formulated here is a hypothetical one. It would be interesting, thus, to extend this research with a study that assesses the robustness of the results found by means of supporting the proposed model with real data. The results, nonetheless, although theoretically obtained, may prove to be important for operational managers in manufacturing units, interested in optimizing transportation costs and delivery time, and implicitly, in optimizing profits. Furthermore, the proposed model is limited to vagueness and randomness only, whereas in real-world problems, the DM may be facing multi-choices situations. By multi-choice we mean a situation wherein the DM has more than one choice, i.e., the demand is not fixed by a crisp number and the DM has more than one demand point. Future research studies could also consider expanding the proposed model to explore production costs and inventory costs. From a methodological point of view, it is to be noted that the fuzzy goal programming model is limited to the linear membership function only; hence, future studies could also explore the role of other membership functions in this model.

\section{Conclusion}

The efficiency and effectiveness of the supply chain are continuallybeing threatened by various sources of uncertainty, which may originate from the demand side, supply side, manufacturing process, and planning and control systems. Uncertainty may lead to delays and bottlenecks and may also hinder the overall performance of the supply chain. It is thus, necessary to find ways to control it. This paper addresses the demand- and supplyrooted uncertainty. In order to cope with uncertainty within the constrained multi-objective supply chain network, this paper aims to develop a fuzzy goal programming methodology with solution procedures.

It is not always possible to find efficient solutions for the multi-objective supply chain network problems which integrate procurement, production, and distribution planning activities together. Hence, by using a fuzzy set theory approach, we can find a compromise solution which is acceptable to the decision-maker. In this paper, the parameters are represented by fuzzy numbers and are transformed into their deterministic form through a ranking function approach. Also, in formulating the real-world problems, there may be situations when we do not precisely know the right-hand side of the constraints; to overcome this situation, we have considered these parameters as random variables, which follow a Pareto distribution, with known mean and variance. The uncertainty of the fuzzy type is modelled using a probabilistic linearly-constrained approach with membership goal function. The simple additive GP approach solves the crisp deterministic model, the weighted GP approach, and the pre-emptive GP approach. It is believed that by adopting the developed approaches, the company's profits will soar and allow to achieve sufficient savings in the SCN. Furthermore, it is hoped that the developed probabilistic fuzzy goal decision-making methodology will open up new possibilities in the study of multi-criteria decision-making problems and can be used in many practical field problems, such as assignment problems, transportation problems, plant management, planning of resource allocation, travelling salesman problems, and so on, when the right-hand side of the constraints is not known exactly. 


\section{References}

1. G. T. M. Hult, C. W. Craighead and D. J. Ketchen, Risk uncertainty and supply chain decisions: a real options perspective, Decision Sciences 41(3) (2010) 435-458.

2. F. J. Quinn, What's the buzz? Logistics Management 36(2) (1997) 43-47.

3. R. S. Bindu, and B.B. Ahuja, Vendor Selection in Supply Chain Using Relative Reliability Risk Evaluation, Journal of Theoretical \& Applied Information Technology 16(2) (2010) 145-152.

4. F. Altiparmak, M. Gen, L. Lin and T. Paksoy, A genetic algorithm approach for multi-objectiveoptimization of supply chain networks, Computers \& Industrial Engineering 51(1) (2006) 196-215.

5. L.A. Zadeh, Fuzzy Sets, Information and Control 8 (1965) 338-353.

6. L. A. Zadeh and R. E. Bellman, Decision Making in a Fuzzy Environment, Management Sciences 17 (1970) 141164.

7. M. Sakawa, Fuzzy Sets and Interactive Multi-objective Optimization, (Plenum Press, New York, 1993).

8. M. Sakawa, I. Nishizaki and Y. Uemura, Interactive fuzzy programming for multi-level linear programming problems with fuzzy parameters, Fuzzy Sets System 109(1) (2000) 03-19.

9. A. Biswas and N. Modak, A Fuzzy Goal Programming Method for Solving Chance Constrained Programming with Fuzzy Parameters, In: Balasubramaniam, P. (ed.) Control, Computation and Information Systems. (Communications in Computer and Information Science, vol. 140. Springer, Berlin, Heidelberg, 2011).

10. S. K. Roy, D. R. Mahapatra and M. P. Biswal, Multi-choice stochastic transportation problem involving exponential distribution, Journal of Uncertain Systems 6(3) (2012) 200-213.

11. D. R. Mahapatra, S. K. Roy and M. P. Biswal, Multichoice stochastic transportation problem involving extreme value distribution, Applied Mathematical Modelling 37(4) (2013) 2230-2240.

12. M. P. Biswal and H. K. Samal, Stochastic transportation problem with Cauchy random variables and multi-choice parameters, Journal of Physical Science 17(1) (2013) 117-130.

13. S. K. Barik, Probabilistic Fuzzy Goal Programming Problems Involving Pareto Distribution: Some Additive Approaches, Fuzzy Information and Engineering 7(2) (2015) 227-244.

14. S. Gupta, I. Ali and A. Ahmed, Multi-objective capacitated transportation problem with mixed constraint: a case study of certain and uncertain environment, OPSEARCH (2018) 1-31. [https://doi.org/10.1007/s12597-0180330-4]

15. B. M. Beamon, Supply chain design and analysis: Models and methods, International Journal of Production Economics 55(3) (1998) 281-294.

16. Z. Shen, Integrated supply chain design models: a survey and future research directions, Journal of Industrial and Management Optimization 3(1) (2007) 1-27.

17. J. Mula, D. Peidro, M. Díaz-Madroñero and E. Vicens, Mathematical programming models for supply chain production and transport planning, European Journal of Operational Research 204(3) (2010) 377-390.

18. E. Sabri and B. M. Beamon, A Multi-objective approach to simultaneous strategic and operational planning in supply chain design .Omega - The International Journal of Management Science, 28 (1) (2000) 581-598.

19. D. Bredstrom and M. Ronnqvist, Integrated production planning and route scheduling in pulp mill industry. In: Proceedings of the 35th Annual Hawaii International Conference on System Sciences (HICSS, 2002), pp. 16061614.

20. J. H. Ryu, V. Dua and E. N. Pistikopoulos, A bilevel programming framework for enterprise-wide process networks under uncertainty, Computers \& Chemical Engineering, 6(7) (2004) 1121-1129.

21. Y. B. Park, An integrated approach for production and distribution planning in supply chain management, International Journal of Production Research 43(1) (2005) 1205-1224.

22. H. C. Oh and I. A. Karimi, Global multiproduct production-distribution planning with duty drawbacks, AIChE Journal 52(2) (2006) 595-610.

23. R. A. Aliev, B. Fazlollahi, B. G. Guirimov and R.R. Aliev, Fuzzy-genetic approach to aggregate productiondistribution planning in supply chain management, Information Sciences, 17(7) (2007) 4241-4255.

24. E. Roghanian, S. J. Sadjadi and M. B. Aryanezhad, probabilistic bi-level linear multi-objective programming problem to supply chain planning, Applied Mathematics and Computation, 188(1) (2007) 786-800.

25. J. Xu, Q. Liu and R. Wang, A class of multi-objective supply chain networks optimal model under random fuzzy environment and its application to the industry of Chinese liquor, Information Sciences 178(8) (2008) 2022-2043. 
26. H. Selim and I. Ozkarahan, A supply chain distribution network design model: an interactive fuzzy goal programming-based solution approach, The International Journal of Advanced Manufacturing Technology 36(3) (2008) 401-418.

27. M. S. Pishvaee and S. A. Torabi, A possibilistic programming approach for closed-loop supply chain network design under uncertainty, Fuzzy sets and systems, 161(20) (2010) 2668-2683.

28. W. C. Yeh and M. C. Chuang, Using multi-objective genetic algorithm for partner selection in green supply chain problems, Expert Systems with applications 38(4) (2011) 4244-4253.

29. T. F. Liang, Application of fuzzy sets to manufacturing/distribution planning decisions in supply chains, Information Sciences 181(4) (2011) 842-854.

30. B. Sarkar, A production-inventory model with probabilistic deterioration in two-echelon supply chain management, Applied Mathematical Modelling 37(5) (2013) 3138-3151.

31. G. R. Nasiri, R, Zolfaghari and H. Davoudpour, An integrated supply chain production-distribution planning with stochastic demands, Computers \& Industrial Engineering 77(1) (2014) 35-45.

32. A. Jindal, K. S. Sangwan and S. Saxena, Network design and optimization for multi-product, multi-time, multiechelon closed-loop supply chain under uncertainty, Procedia CIRP 29(1) (2015) 656-661.

33. S. J. Kim and B. Sarkar, Supply Chain Model with Stochastic Lead Time, Trade-Credit Financing, and Transportation Discounts, Mathematical Problems in Engineering (2017) 1-14. [DOI: org/10.1155/2017/6465912]

34. B. Sarkar, A. Majumder, M. Sarkar, B. K. Dey and G. Roy, Two-echelon supply chain model with manufacturing quality improvement and setup cost reduction, Journal of Industrial \& Management Optimization 13(2) (2017) 1085-1104.

35. R. V. Latpate and S. S. Kurade, Fuzzy MOGA for supply chain models with Pareto decisión space at different $\alpha-$ cuts, The International Journal of Advanced Manufacturing Technology, 9(12) (2017) 3861-3876.

36. S. Gupta, I. Ali and A. Ahmed, Efficient Fuzzy Goal Programming Model for Multi-objective Production Distribution Problem, International Journal of Applied and Computational Mathematics, 4: 76 (2018). [https://doi.org/10.1007/s40819-018-0511-0]

37. B. Sarkar, S. Saren, D. Sinha and S. Hur, Effect of unequal lot sizes, variable setup cost, and carbon emission cost in a supply chain model Mathematical Problems in Engineering (2015). Article ID 469486.

38. B. Sarkar, Supply chain coordination with variable backorder, inspections, and discount policy for fixed lifetime products, Mathematical Problems in Engineering (2016). Article ID 6318737.

39. B. Sarkar and A. S. Mahapatra, Periodic review fuzzy inventory model with variable lead time and fuzzy demand, International Transactions in Operational Research 24(5) (2017)1197-1227.

40. B. Sarkar, M. Ullah and N. Kim Environmental and economic assessment of closed-loop supply chain with remanufacturing and returnable transport items Computers \& Industrial Engineering 111(1) (2017) 143-163.

41. H. N. Soni, B, Sarkar and M. Joshi, Demand uncertainty and learning in fuzziness in a continuous review inventory model, Journal of Intelligent \& Fuzzy Systems 33(4) (2017) 2595-2608.

42. A. Charnes and W. W. Cooper, Management Models of Industrial Applications of Linear Program. (Wiley, New York, 1968).

43. S. M. Lee, Goal Programming for Decision Analysis, (Philadelphia: Auerbach Publishers, 1972).

44. J. P. Ignizio, Goal Programming and Extensions. (Lexington: D.C. Heath, 1976).

45. H. J. Zimmermann, Fuzzy Programming and Linear Programming with Several Objective Functions, Fuzzy Sets and Systems 1 (1978) 45-55.

46. G.B. Dantzig and A. Mandansky, On the solution of two-stage linear programs under uncertainty, In I. J. Neyman (Ed.), Proc. 4th Berkeley Symposium on (Mathematical Statistics and Probability, 1961), pp. 165-176.

47. A. Charnes and W. W. Cooper, Management models and industrial applications of linear programming, (Wiley, New York, 1961).

48. B. Contini, A stochastic approach to goal programming, Operations Research 16(3) (1968) 576-586.

49. I. M. Stancu-Minasian, Overview of different approaches for solving stochastic programming problems with multiple objective functions, In Stochastic versus fuzzy approaches to multi-objective mathematical programming under uncertainty (The Netherlands, Springer, 1990), pp. 71-101. 
50. P. Singh, S. Kumari and P. Singh, Fuzzy Efficient Interactive Goal Programming Approach for Multi-Objective Transportation Problems, International Journal of Applied and Computational Mathematics 3(2) (2016) 5055251.

51. S. Abbasbandy, and T. Hajjari, A new approach for ranking of trapezoidal fuzzy number,. Computers \& Mathematics with Applications 57(3) (2009) 413-419.

\section{Appendix}

Before formulating the problem of interest, we introduce the basic definitions of fuzzy sets, fuzzy numbers, and so forth, which are reproduced here from Abbasbandy and Hajjari ${ }^{51}$ as follows:

Definition 1: A fuzzy number is a fuzzy set like $u: \mathfrak{R} \rightarrow I=[0,1]$, which satisfies:

1. $u$ is upper semi-continuous,

2. $u(x)=0$ outside some interval $[a, d]$,

3. There are real numbers $a$; $b$ such that $a \leq b \leq c \leq d$ and

a. $u(x)$ is monotonic increasing on $[a, b]$,

b. $u(x)$ is monotonic decreasing on $[c, d]$,

c. $u(x)=1, b \leq x \leq c$.

The membership function $u$ can be expressed as:

$$
u(x)= \begin{cases}u_{L}(x), & a \leq x \leq b \\ 1, & b \leq x \leq c \\ u_{R}(x), & c \leq x \leq d \\ 0, & \text { otherwise }\end{cases}
$$

where $u_{L}:[a, b] \rightarrow[0,1]$ and $u_{R}:[c, d] \rightarrow[0,1]$ are the left and right membership functions of the fuzzy number $u$.

Definition 2:A fuzzy number $u$ in parametric form is a pair $(\underline{u}, \bar{u})$ of functions $\underline{u}(r), \bar{u}(r), 0 \leq r \leq 1$, which satisfy the following requirements:

1. $\underline{u}(r)$ is a bounded monotonic increasing left continuous function,

2. $\bar{u}(r)$ is a bounded monotonic decreasing left continuous function,

3. $\underline{u}(r) \leq \bar{u}(r), 0 \leq r \leq 1$.

The trapezoidal fuzzy number $u=(m, n, \alpha, \beta)$, with two defuzzifierm,nand left fuzziness $\alpha>0$ and right fuzziness $\beta>0$ is a fuzzy set where the membership function is as: 


$$
u(x)= \begin{cases}\frac{1}{\alpha}(x-m+\alpha), & m-\alpha \leq x \leq m \\ 1, & x \in[m, n] \\ \frac{1}{\beta}(n-x+\beta), & n \leq x \leq n+\beta \\ 0, & \text { otherwise }\end{cases}
$$

and its parametric form is:

$$
\underline{u}(r)=m-\alpha+\alpha r, \quad \bar{u}(r)=n+\beta-\beta r
$$

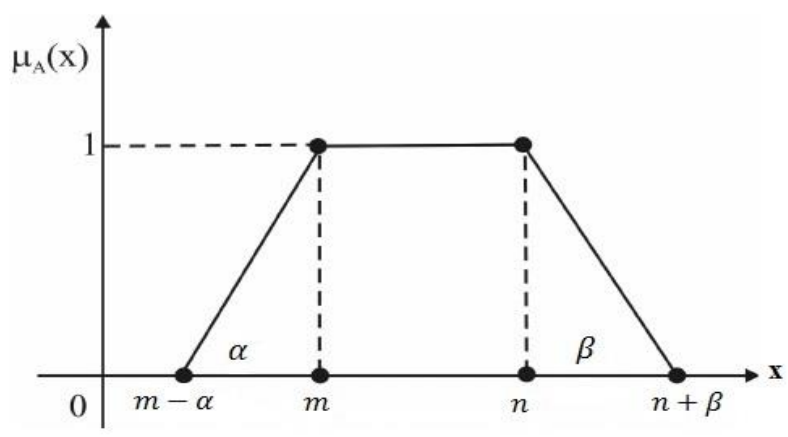

Fig. 3. Trapezoidal LR-Fuzzy number

\section{Definition 3: Magnitude of the Trapezoidal Fuzzy Number:}

If $\tilde{A}=(m, n, \alpha, \beta)$ is a trapezoidal fuzzy number with two defuzzifiers $m$, $n$, and left fuzziness $\alpha>0$ and right fuzziness $\beta>0$ with parametric form $\tilde{A}=(A(r), \bar{A}(r))$, the magnitude of the trapezoidal fuzzy number $\tilde{A}$ is defined as:

$$
\Re(\tilde{A})=\frac{1}{2}\left(\int_{0}^{1}(\underline{A}(r), \bar{A}(r)+m+n) f(r) d r\right)
$$

where $r \in[0,1], A(r)=m-\alpha+\alpha r$, and $\bar{A}(r)=m+\beta-\beta r$. By taking $f(r)=r$ in Equation (2), the rank of an arbitrary trapezoidal fuzzy number $\tilde{A}=(m, n, \alpha, \beta)$ is given by:

$$
\Re(\tilde{A})=\frac{m+n}{2}+\frac{\beta-\alpha}{12}
$$

Equation (3) is the desired ranking function to get the crisp value of the fuzzy number. 
From: em.ijufks.0.5c9431.5fdf9640@editorialmanager.com

[em.ijufks.0.5c9431.5fdf9640@editorialmanager.com] on behalf of Int. J. of Uncertainty, Fuzziness \& Knowledge-Based Systems (IJUFKS) [em@editorialmanager.com]

Sent: 15 July 2018 23:19

To: V. Charles Charles

Subject: Your Submission: IJUFKS-D-17-00047R1

CC: rommel@wiwi.uni-frankfurt.de

Ref.: Ms. No. IJUFKS-D-17-00047R1

A fuzzy goal programming approach for solving multi-objective supply chain network problems with Pareto-distributed random variables

International Journal of Uncertainty, Fuzziness and Knowledge-Based Systems

Dear Dr. Vincent Charles,

I am pleased to inform you that your work has now been accepted for publication in

International Journal of Uncertainty, Fuzziness and Knowledge-Based Systems.

It was accepted on Jul 10, 2018.

If you wish to have your article published as Open Access, please note the Article-Processing Charge (APC) is USD2000. You may contact us or visit

http://www.worldscientific.com/page/open for more details.

Comments from the Editor and Reviewers can be found below.

Thank you for submitting your work to this journal.

Yours sincerely,

Bernadette Bouchon-Meunier

Editor-in-Chief

International Journal of Uncertainty, Fuzziness and Knowledge-Based Systems

Comments from the Editors and Reviewers:

Reviewer \#1: Dear Author,

The paper is well-organized now. The paper can be accepted for publication.

Reviewer \#2: The authors have addressed all reviewers' comments satisfactorily and I recommend publishing this paper in IJUFKS in the current form. 
Preprint of an article published in the International Journal of Uncertainty, Fuzziness and KnowledgeBased Systems, [https://doi.org/10.1142/S0218488519500259] @ [copyright World Scientific Publishing Company] [https://www.worldscientific.com/worldscinet/ijufks] 